\title{
High Vacuum Standard and Its Use
}

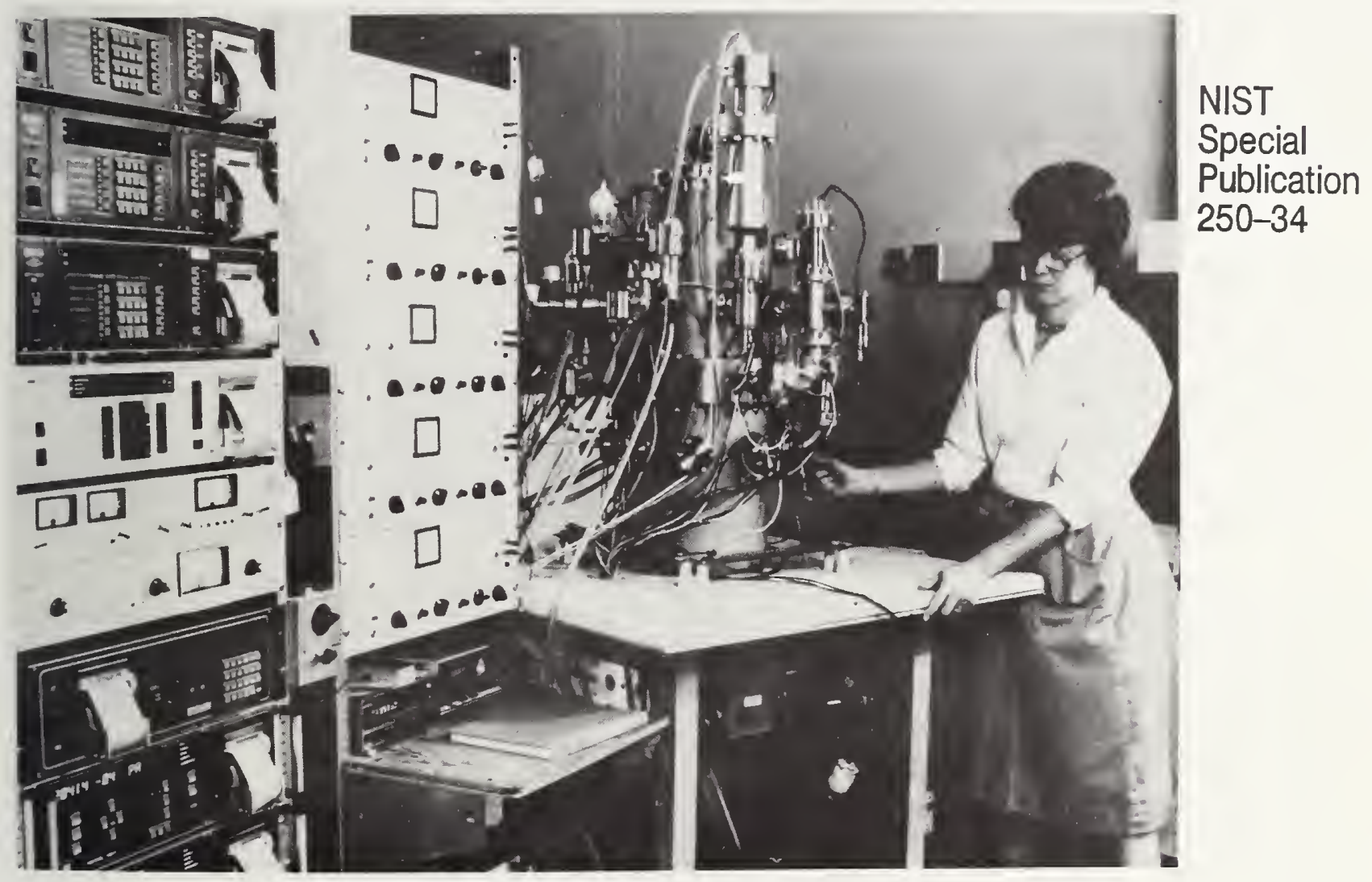

Sharrill Dittmann

U.S. Department of Commerce

National Institute of Standards and Technology (formerly National Bureau of Standards) 


\section{Center for Basic Standards}

The Center for Basic Standards develops and maintains the scientific competencies and laboratory facilities necessary to preserve and continue to refine the base physical quantities upon which the Nation's measurement system is constructed. The Center is responsible for the standards of voltage, current, resistance and impedance, temperature, vacuum, leak rate, pressure, mass, length, time and frequency. The Center collaborates closely with the standardizing laboratories of other countries to ensure that measures used in international trade are fully compatible. The Center also performs research at the frontiers of physics in order to improve measurement capability and quantitative understanding of basic physical processes that underlie measurement science.

\section{Electricity Division}

Maintains and improves the national standards of electrical measurements; conducts experiments to realize the electrical units in terms of the mechanical units; develops stable electrical standards and improved methods for the dissemination of the units of electrical measurements; determines fundamental physical constants related to electrical units; develops instrumentation for precise electrical measurements directly referenced to the national standards; implements techniques for their use and puts them into practical applications; assists in applying scientific and technological development to measurement problems, especially in other areas of NIST research.

\section{Temperature and Pressure Division}

Maintains and improves the national standards of temperature and pressure; conducts research towards the development of new concepts for these standards; calibrates practical standards for the U.S. scientific and technical community in terms of the primary standards; develops methods and devices to assist user groups in the assessment and enhancement of the accuracy of their measurements of temperature and pressure; prepares and promulgates evaluations and descriptions of temperature and pressure measurement processes; coordinates these standards and measurement methods nationally and internationally; and determines the accuracy of the national standards of temperature and pressure with respect to fundamental thermodynamic relations.

\section{Length and Mass Division}

Develops and uses the competence necessary to implement a more accurate measurement system for length and mass; applies research, utilizing the most advanced technology available, to the improvement of our present standards and devises new standards and new methods for their transfer.

\section{Time and Frequency Division}

Maintains, develops, and improves the national standards for time (which are coordinated with the United States Naval Observatory) and frequency, and the time scales based on these standards; carries out research in areas of importance to the further fundamental improvement of frequency standards and their applications focusing on microwave and laser devices, atomic and molecular resonances, and the measurement of fundamental physical phenomena and constants; adapts time and frequency standard devices and concepts to special scientific and technological demands; develops time and frequency measurement methods in the radio frequency, microwave, infrared, and visible radiation regions; coordinates the national time and frequency standards, time scales, and measurement methods nationally and internationally in conjunction with the United States Naval Observatory; operates time and frequency dissemination services, such as radio stations and broadcasts, for the purpose of traceability to the national standards of time and frequency.

\section{Quantum Physics Division}

Engages in research in atomic and molecular physics at the forefront of the field, and performs basic, highly accurate measurements and theoretical analyses that help establish a reliable foundation for scientific and technological measurement and data.

\section{Quantum Metroiogy Division}

Engages in forefront research in quantum metrology; contributes to new determinations of the fundamental physical constants, and the extension and refinement of the electromagnetic scale and devises, where possible, tests of basic symmetries and invariances. 


\section{NIST MEASUREMENT SERVICES: High Vacuum Standard and Its Use}

\section{Sharrill Dittmann}

Center for Basic Standards

National Measurement Laboratory

National Institute of Standards and Technology

Gaithersburg, MD 20899

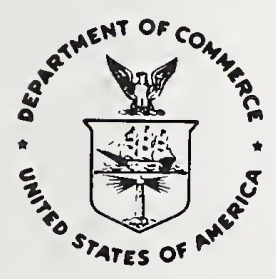

NOTE: As of 23 August 1988, the National Bureau of Standards (NBS) became the National Institute of Standards and Technology (NIST) when President Reagan signed into law the Omnibus Trade and Competitiveness Act.

U.S. DEPARTMENT OF COMMERCE, Robert A. Mosbacher, Secretary Ernest Ambler, Acting Under Secretary for Technology NATIONAL INSTITUTE OF STANDARDS AND TECHNOLOGY Raymond G. Kammer, Acting Director 


\section{Library of Congress Catalog Card Number: 88-600605}

National Institute of Standards and Technology Special Publication 250-34 Natl. Inst. Stand. Technol. Spec. Publ. 250-34, 68 pages (March 1989) CODEN: NSPUE2 
Calibrations and related measurement services of the National Institute of Standards and Technology provide the means for makers and users of measuring tools to achieve levels of measurement accuracy that are necessary to attain quality, productivity and competitiveness. These requirements include the highest levels of accuracy that are possible on the basis of the most modern advances in science and technology as well as the levels of accuracy that are necessary in the routine production of goods and services. More than 300 different calibrations, measurement assurance services and special tests are available from NIST to support the activities of public and private organizations. These services enable users to link their measurements to the reference standards maintained by NIST and, thereby, to the measurement systems of other countries throughout the world. NIST Special Publication 250, NIST Calibration Services Users Guide, describes the calibrations and related services that are offered, provides essential information for placing orders for these services and identifies expert persons to be contacted for technical assistance.

NIST Special Publication 250 has recently been expanded by the addition of supplementary publications that provide detailed technical descriptions of specific NIST calibration services and, together with the NIST Calibration Services Users Guide, they constitute a topical series. Each technical supplement on a particular calibration service includes:

- specifications for the service

- design philosophy and theory

- description of the NIST measurement system

- NIST operational procedures

- measurement uncertainty assessment

error budget

systematic errors

random errors

- NIST internal quality control procedures

The new publications will present more technical detail than the information that can be included in NIST Reports of Calibration. In general they will also provide more detail than past publications in the scientific and technical literature; such publications, when they exist, tend to focus upon a particular element of the topic and other elements may have been published in different places at different times. The new series will integrate the description of NIST calibration technologies in a form that is more readily accessible and more useful to the technical user.

The present publication, SP 250-34, NIST Measurement Services: The National Institute of Standards and Technology High Vacuum Standard and Its Use, is one of approximately 20 documents in the new series published or in preparation by the Center for Basic Standards. It describes calibration technology and procedures utilized in connection with NIST Service Identification Numbers from $30030 \mathrm{C}$ to $30050 \mathrm{~S}$ listed in the NIST Calibration Services Users Guide 1986-88/Revised (pages 45-46). Inquiries concerning the contents of these 
documents may be directed to the author or to one of the technical contact persons identified in the Users Guide (SP - 250).

Suggestions for improving the effectiveness and usefulness of the new series would be very much appreciated at NIST. Likewise, suggestions concerning the need for new calibration services, special tests and measurement assurance programs are always welcome.

Joe Simmons, Chief

Office of Physical Measurement Services

Katharine Gebbie, Director

Center for Basic Standards 
Preface

I. Introduction 1

II. Description of the NIST Vacuum Calibration Service 1

III. Theory, Design Philosophy and Description of the Calibration System

The Chamber

The Flowmeter

The Orifice

Extension to Lower Pressures

Calibrations at Higher Pressures

Component Selection Criteria

IV. Operational Procedures for Calibration Using the NIST High Vacuum Standard

Installation and Preparation of Gages

The Day Prior to the Calibration

The Morning of the Calibration

Measured Flow to Upper Chamber

Measured Flow to Lower Chamber

Steady Flow Generator

Shutting Down

Venting the System

Data Analysis

V. Assessment of Uncertainties 23

Systematic Errors $\quad 23$

Random Errors $\quad 27$

$\begin{array}{ll}\text { Summary of Errors } & 28\end{array}$

$\begin{array}{lr}\text { VI. Quality Control } & 30\end{array}$

Comparisons Against Additional NIST Primary Standards 30

International Comparisons $\quad 31$

Continuous, Repeated Calibrations of Vacuum Gages 32

Additional Checks $\quad 33$

$\begin{array}{lr}\text { VII. Needs and Plans } & 34\end{array}$

$\begin{array}{lr}\text { VIII. Acknowledgments } & 35\end{array}$

IX. References $\quad 36$

$\begin{array}{ll}\text { X. Bibliography } & 37\end{array}$ 
XI. Appendices

A. Sample Report of Calibration for Ionization Gage

B. Sample Report of Calibration for Molecular Drag Gage

$A-1$

C. Dimensions and Conductance of the Orifice in the NIST Dynamic Expander 


\section{LIST OF TABLES}

Page

I. Summary of the vacuum calibration service 2

II. Primary standard configurations used for calibrations 15

III. Primary standard nonlinearities 25

IV. Uncertainties of the NIST high vacuum standard with nitrogen 29

v. Results of first international intercomparison 31

VI. Ion gage sensitivities, nitrogen gas 33

\section{LIST OF FIGURES}

1. Schematic of the primary high vacuum standard 39

2. Schematic of the vacuum chamber 40

3. Axial section of the orifice plate 41

4. Representative measured low-pressure nitrogen sensitivities for different ion gages

5. Deviations from initial value for calibrations of five molecular drag gages

6. Ion gage sensitivity in nitrogen for two ultra-high vacuum ionization gages

7. Detail of central duct through orifice plate 

Vacuum measurements are an important tool for many segments of the American economy and for American defense efforts. The accuracy of these measurements affects a large variety of industries ranging from space simulation to semiconductor processing. The National Institute of Standards and Technology provides calibrations for a variety of vacuum gages over a broad range of pressures - from atmospheric pressure (about $10^{5}$ pascal) to high vacuum (about $10^{-6}$ pascal).

This document presents an in-depth discussion of the NIST primary high vacuum standard, used between $10^{-6}$ and $10^{-2} \mathrm{~Pa}$. Included are discussions of the theory, design, and construction of the standard. In addition, the systematic and random errors in the standard and the methods used to check the accuracy of the standard are presented.

Also included is a brief discussion of the molecular drag gage and its performance as a transfer standard between $10^{-4}$ and $10^{-1} \mathrm{~Pa}$.

\section{DESCRIPTION OF THE NIST VACUUM CALIBRATION SERVICE}

The National Institute of Standards and Technology provides calibrations of suitable high vacuum gages over the range $10^{-6}$ to $10^{-1} \mathrm{~Pa}$ (pascal) (10-8 to $10^{-3}$ Torr) using gases compatible with the standard. Gages must be stable and capable of precision at the level of a few percent to be considered suitable for calibration. Molecular drag gages (MDGs) are calibrated against the NIST primary high vacuum standard at $5 \times 10^{-3} \mathrm{~Pa}\left(4 \times 10^{-5}\right.$ Torr $)$. Hot cathode ionization gages (IGs) are calibrated against calibrated molecular drag gages over the range $10^{-4}$ to $10^{-1} \mathrm{~Pa}$. They are calibrated against the NIST primary high vacuum standard over the range $10^{-6}$ to $10^{-4} \mathrm{~Pa}\left(10^{-8}\right.$ to $10^{-6}$ Torr $)$. These services are summarized below: 
TABLE I. Summary of the Vacuum Calibration Service

\begin{tabular}{|c|c|c|c|}
\hline Sensor & $\begin{array}{c}\text { Calibration } \\
\text { Range }\end{array}$ & Standard & Uncertainty \\
\hline & $\mathrm{Pa}$ & & percent \\
\hline MDG & $5 \times 10^{-3}$ & $\begin{array}{l}\text { Primary high } \\
\text { vacuum }\end{array}$ & $1.4-1.6$ \\
\hline IG & $10^{-4}-10^{-1}$ & Calibrated MDG & $1.4-2.6$ \\
\hline IG & $10^{-6}-10^{-4}$ & $\begin{array}{l}\text { Primary high } \\
\text { vacuum }\end{array}$ & $1.4-5.2$ \\
\hline
\end{tabular}

If calibration of a gage other than a hot cathode ionization gage or a molecular drag gage is desired, contact the Temperature and Pressure Division at the address below.

The Report of Calibration for an MDG gives the effective accommodation coefficient or calibration coefficient of the rotor, and a discussion of the care and use of the gage for best results. The Report of Calibration for an ionization gage gives the correction factor for the gage's indicated pressure as determined as a function of pressure and the characteristics of the controller (grid and filament biases and electrometer performance if applicable), and provides a discussion of the treatment and use of the gage for best results. See Appendices A and B for sample reports.

For information concerning these services or to schedule a calibration, please contact Temperature and Pressure Division, Bldg. 220, Room A55, National Institute of Standards and Technology, Gaithersburg, MD 20899.

\section{THEORY, DESIGN PHILOSOPHY AND DESCRIPTION OF THE CALIBRATION SYSTEM}

High vacuum calibrations are performed at the National Institute of Standards and Technolgoy (NIST) with the Primary High Vacuum Standard - an orifice-flow system (see fig. 1) - between $10^{-6}$ and $10^{-2} \mathrm{~Pa}$ and against a group of calibrated molecular drag gages (also called spinning rotor gages) between $10^{-4}$ and $10^{-1} \mathrm{~Pa}$. The three main components in the primary standard are the vacuum chamber, the flowmeter and the orifice. Pressures are generated by producing a known flow of gas which passes through an orifice of known conductance, thereby producing a known pressure drop across the orifice. This pressure drop is calculated from first principles and constitutes a primary standard. The details of the system are discussed below. 
The design of the vacuum chamber, illustrated in figure 2, is largely determined by the need to maintain a low background pressure, to provide room to mount the gages to be calibrated, and to maintain a geometry where the orifice conductance calculations will be valid and the necessary degree of pressure uniformity can be assured. The chamber is in two cylindrical halves, each $27 \mathrm{~cm}$ in diameter and $34 \mathrm{~cm}$ long, separated by a central wall with the orifice in the center. This size chamber permits the incorporation of eight $3.5-\mathrm{cm}$ i.d. mounting ports on the upper half $13.3 \mathrm{~cm}$ above the plane of the orifice. A circular baffle $5 \mathrm{~cm}$ below the top of the upper chamber insures that gas molecules entering through the top of the chamber from the flowmeter will experience several collisions with the chamber walls before entering a gage or passing through the orifice at the bottom. These collisions are essential to insure the random distribution of molecular velocities, which is necessary for pressure uniformity and which is assumed in the conductance calculation.

As discussed below, the uniform distribution of molecular flux will be perturbed by the molecules entering the chamber from the inlet line and by those escaping through the orifice. These perturbations can be kept within acceptable bounds by using an orifice whose area is a small fraction of the surface area of the chamber. At the same time, the orifice conductance must be large enough to maintain a low background partial pressure and ensure a high enough flow that gage pumping and outgassing are minor perturbations. In our system, the compromise used is a nominal $1.1-\mathrm{cm}$ diameter orifice, described in detail below, with a nitrogen conductance of about $12 \times 10^{-3} \mathrm{~m}^{3} \mathrm{~s}^{-1}$ and an area of $0.03 \%$ of the chamber surface.

Because of the finite pumping speed available at the lower chamber, some fraction of the molecules passing through the orifice from the upper chamber will return back through the orifice. This is a second order perturbation that can be readily accounted for if these returning molecules originate from a uniform flux distribution. This is achieved by making the lower chamber an almost symmetric duplicate of the upper chamber, with a baffle $12 \mathrm{~cm}$ above the inlet of the nominal $0.5 \mathrm{~m}^{3} \mathrm{sec}^{-1}$ turbomolecular pump attached to the bottom of the chamber. The chamber is not perfectly symmetrical as the baffle is located $24 \mathrm{~cm}$ below the orifice (the top baffle is $29 \mathrm{~cm}$ above the orifice). The effective rate of exhaust from the lower chamber has been measured to be $0.3 \mathrm{~m}^{3} \mathrm{~s}^{-1}$ for nitrogen. The pump speed is somewhat limited by the baffle in 
the lower chamber and by the $15-\mathrm{cm}$ i.d. connection between the lower chamber and the pump. The turbomolecular pump was chosen for its stable high pumping speed, low base pressure, and compatibility with all gases.

Ultra-high vacuum construction practices are employed throughout the chamber; the chamber material is type 304 stainless steel, only all-metal seals are used, and the chamber and all gages are baked at. about $250{ }^{\circ} \mathrm{C}$ after each venting to air. However, the small orifice clearly would restrict the attainment of a low base pressure in the upper chamber. Therefore, the orifice is contained in a plate that seals into a gallium-filled groove located in the central wall as illustrated in figure 2. During pump-down or bakeout the orifice plate can be lifted through a bellows at the top of the chamber, opening a $12.7-\mathrm{cm}$ hole between the upper and lower chambers. For the gallium to form a seal when the orifice plate is lowered, it must remain supercooled for prolonged periods below its $302.95 \mathrm{~K}$ melting temperature. Should the gallium freeze, the edge of the orifice plate would fail to make an integral seal with the central wall. Leaks of $10 \mathrm{~cm}^{3} \mathrm{~s}^{-1}$ or larger will have a significant effect on our measurements. In 4 years of operation we have never observed any erratic calibration data for our check standards which would indicate unreproducible sealing or failure of the seal. Nor have we seen any evidence of gallium vapor in the chamber, which is consistent with gallium's predicted vapor pressure of $10^{-28} \mathrm{~Pa}$ at room temperature.

This system routinely attains base pressures of about $10^{-8} \mathrm{~Pa}$, the residual gas being almost entirely hydrogen. The base pressure in the upper chamber increases by about a factor of two when the orifice plate is lowered and sealed in the gallium groove.

\section{THE FLOWMETER}

The flowmeter is used to generate a known flow of gas through the orifice which produces a pressure drop across the orifice. The differential pressure thus produced plus the pressure below the orifice is measured by the gage under test. The flow is produced by a $\mathrm{P}(\mathrm{dV} / \mathrm{dT})$ method in which gas is allowed to leak out of a reservoir which is maintained at a constant pressure by changing its volume through the advance of a piston. The time taken for the piston to advance a known distance is measured and the flow is thus known. This use of the orifice-flowmeter system offers three distinct advantages over a static expansion system. First, because this is a steady flow system, transient behavior associated with adsorbtion and desorbtion become negligible 
after a sufficiently long time following establishment of a steady gas flow. Second, stable pressures are readily generated for long periods of time. Third, the only dimensions which need to be characterized are those of the orifice and the volume of the piston, and these are not dependent on the position of valves. A detailed examination of the flowmeter is found in Ref.1.

Before examining the flowmeter, we briefly review the equations used to calculate the flow rate of the gas and the pressure drop across the orifice. The equations used are:

for the throughput $Q$,

$$
\mathrm{Q}=\mathrm{P}_{\mathrm{fm}}[(\mathrm{dV}) /(\mathrm{dt})]\left(\mathrm{T}_{\mathrm{ch}} / \mathrm{T}_{\mathrm{fm}}\right) \quad \text { in } \mathrm{Pa} \mathrm{m} \mathrm{m}^{3} \mathrm{~s}^{-1}
$$

for the orifice conductance $C$,

$$
\mathrm{C}=\mathrm{C}^{*}\left(\mathrm{~T}_{\mathrm{ch}} / 298.15 \mathrm{~K}\right)^{1 / 2} \quad \text { in } \mathrm{m}^{3} \mathrm{~s}^{-1}
$$

for the pressure at the upstream side of the orifice,

$$
\mathrm{P}=(\mathrm{Q} / \mathrm{C}) \mathrm{R}_{\mathrm{P}} /\left(\mathrm{R}_{\mathrm{P}}-1\right) \quad \text { in } \mathrm{Pa}
$$

where $Q$ is the throughput of the gas, $C^{*}$ is the conductance of the orifice, (I in fig. 1) at $298.15 \mathrm{~K}$ for the gas in question, $\mathrm{P}$ is the pressure on the upstream side of the orifice, and $R_{P}$ is the ratio of the pressures in the upper and lower chambers. The superscript "*" refers to quantities calculated at $298.15 \mathrm{~K}$, the subscript "fm" refers to quantities measured in the flowmeter and the subscript "ch" refers to quantities measured in the chamber.

All letter references in the following discussion are those indicated in fig. 1 .

$Q$ is generated as follows. Initially, two interconnected reservoirs ( $B$ and E) are filled to the same pressure from a ballast volume (A). Gas flows from the ballast volume into the reference reservoir (B) and through the working reservoir.(E) into the chamber (H). The rate of flow into the vacuum chamber is regulated by an all-metál leak valve (G). To initiate a calibration, the reference reservoir $(B)$ is isolated. At this time, $P_{f m}$ is measured in the reference reservoir with a capacitance diaphragm gage (CDG) (C). $P_{f m}$ is between 0.07 and $133 \mathrm{kPa}$ and is within the range where the CDGs have adequate accuracy. After the reference reservoir is sealed, the flow from the ballast volume continues into the chamber through the working reservoir (E). Gas purity is continuously monitored with a residual gas analyzer. No special precautions are taken once the gas leaves the high-pressure supply cylinder, but for some gases, it has been found necessary to purchase high purity samples. 
The next step is to isolate the working reservoir (E) from the ballast volume so that flow is out of the working reservoir alone into the chamber. This flow of gas will tend to reduce the pressure in the working reservoir but constant pressure is maintained by advancing a piston ( $F$ ) to displace volume in the working reservoir. The piston enters the working volume through an elastomer and PTFE sliding seal. A differential CDG (D) reads the pressure difference between the two reservoirs and the piston is advanced by a stepping motor in such a manner as to keep the reading of that CDG at zero.

For optimum sensitivity and control, the volume of the piston should be a large fraction of the volume of the working reservoir. This has been achieved without sacrificing a wide range of available flow rates by constructing two working reservoirs in series. Each reservoir has its own piston and the piston areas are $0.8 \mathrm{~cm}^{2}$ and $5.1 \mathrm{~cm}^{2}$. The piston not in use during a measurement is driven into its working reservoir in order to minimize dead volume in the flowmeter. We shall refer to a single working reservoir and piston in this document with the understanding that there are actually two.

The piston is allowed to travel $2.54 \mathrm{~cm}$ as measured by a micrometer screw, at which time the measurement is terminated. The time needed for the piston to complete its travel is monitored and displayed after each turn of the micrometer screw.

The temperatures of the working reservoir, $\mathrm{T}_{\mathrm{fm}}$, and the chamber, $\mathrm{T}_{\mathrm{ch}}$, are rerorded before and after the calibration as is the pressure in the reference reservoir, $P_{f m}$.

\section{THE ORIFICE}

$C$ in eqs (2) and (3) is the conductance of the orifice ( $I$ in fig...1). From theory and dimensional measurements, the conductance of the orifice corresponding to the chamber temperature is calculated for each gas, as indicated in eq (2).

The orifice was designed so that 1 ts conductance could be easily calculated. In addition, it was desirable that its area be a small fraction of the vacuum chamber area and that the desired pressures in the vacuum chamber correspond to the accurate range of the flowmeter.

The orifice, is a sharp-edged hole at the center of a 15.2-cm diameter, 1.27-cm thick, stainless steel plate (fig. 3). The outer edge of the plate includes a lip ( $\mathrm{K}$ in fig. 3) that fits into the gallium-filled groove in the wall between the chamber halves. The plate was fabricated by machining the 
upper side to a depth of $0.61 \mathrm{~cm}$ from the center out to a diameter of $8.89 \mathrm{~cm}$, and a centered $1.12 \mathrm{~cm}$ diameter hole was bored through the plate. The underside of the plate was machined to form a hollow, truncated $80^{\circ}$ half-angle cone, leaving a thickness of $0.74 \mathrm{~mm}$ at the edge of the center hole. The orifice edge region was formed by lapping the hole with a steel ball of $1.587-\mathrm{cm}$ (0.6250 in) diameter to nominally equal depths from above and below. Upon final lapping with an unworn ball, the two concave spherical surfaces thus generated met at a sharp circular edge with a measured diameter of 1.1240 $\mathrm{cm}$ (0.4425 in \pm 0.0003 in) and a computed edge angle of $90.1^{\circ}$. Microscopic examination revealed a clean, sharp, burr-free edge.

Calculation of the orifice conductance is based on the molecular transmission probability approach initiated by Clausing [2]. It assumes free molecular flow and cosine-law scattering at surfaces. A full derivation of the orifice conductance is given in Appendix $C$.

From the work in Appendix $C$ and the dimensions of the orifice, we derive

$$
\mathrm{C}^{*}=0.2464 \cdot \mathrm{S} \quad \mathrm{cm}^{3} \mathrm{~s}^{-1}
$$

where $S$ is the mean molecular speed in $\mathrm{cm} \mathrm{s}^{-1}$. The overall uncertainty in $\mathrm{C}^{*}$ is estimated to be \pm 0.188 , with the largest contribution being 0.148 due to the uncertainty in the measured value of the radius of the hole.

Knowing the orifice conductance, $C$, and the throughput, Q, of gas, we can obtain the pressure difference across the orifice,

$$
\mathrm{P}_{\mathrm{U}}-\mathrm{P}_{\mathrm{L}}=\mathrm{Q} / \mathrm{C} \text {, }
$$

where $P_{U}$ and $P_{I}$ designate the pressures in the upper and lower chambers. Because of the finite pumping speed below the orifice, $P_{L}$ is not negligible: $P_{L}$ is 3.78 of $P_{U}$ for $N_{2}$ in our system. It is difficult to measure $P_{L}$ directly since this would require a gage calibrated below the range of pressures generated by the standard. However, if we can measure the ratio, $R_{P}$, of the pressures above, $\mathrm{P}_{U}$, and below, $\mathrm{P}_{\mathrm{L}}$, the orifice,

$$
R_{P}=P_{U} / P_{L}
$$

then from eqs (5) and (6) we have

$$
\mathrm{P}_{\mathrm{U}}=\mathrm{QR} \mathrm{R}_{\mathrm{P}} / \mathrm{C}\left(\mathrm{R}_{\mathrm{P}}-1\right) \text {. }
$$

The pressure ratio $R_{P}$ is measured by a molecular drag gage that, as shown in figure 2, can be connected through $11 / 2$ - in $(3.8 \mathrm{~cm})$ bakeable valves to one of the gage ports in the upper chamber or to a similar port in the lower chamber. Since the MDG operates at the temperature of the gas and is reproducible at the 18 or better level above $10^{-4} \mathrm{~Pa}$, it can be used to determine $R_{P}$ quite precisely in the high vacuum range. The value of $R_{P} /\left(R_{P}-1\right)$ is quite insensitive to errors in $R_{P}$. A more significant problem is that as 
the pressure is reduced, the random error of the MDG, typically $10^{-6} \mathrm{~Pa}$ or greater, precludes its use for a direct determination of $R_{P}$. $R_{P}$ will be a function only of the orifice conductance and the pump speed, and in the molecular flow range, the only variable can be the turbomolecular pump speed. As detailed below, we have indirectly found the pump speed, and therefore $R_{P}$, to be constant to within a few percent down to a lower chamber pressure of $3 \times 10^{-8} \mathrm{~Pa}$.

\section{EXTENSION TO LOWER PRESSURES}

The lowest usable pressure generated with an orifice-flow standard is determined by the lower limit of acceptable performance of the flowmeter and the base pressure of the vacuum chamber. In the case of the NIST system, this limit is determined by the behavior of the flowmeter.

The base pressure is normally $10^{-8} \mathrm{~Pa}$ and, were it possible, the useful range of the standard could be extended down to $10^{-6} \mathrm{~Pa}$ with the residual gas pressure constituting no more than 18 of the calibration pressure. This has effectively been done by injecting the gas flow into the lower half of the vacuum chamber, which permits using a higher gas flow to generate a given pressure. As a result, the usable range of calibration pressures has been extended two decades lower at the cost of slightly increased uncertainties in the generated pressure. The pressure gradients in the lower chamber preclude the direct calculation of the resultant pressure in the upper chamber. However, we can experimentally determine the ratio of the flows, $R_{F}$, into the two chambers required to generate the same pressure in the upper chamber. A pressure is established by a measured flow, $Q_{U}$, from the flowmeter into the upper chamber. Using the valves identified as $\mathrm{K}$ in figure 1 , the flow, is then redirected from the upper chamber to the lower chamber; the flow is then increased to a value $\mathrm{Q}_{\mathrm{L}}$ until the same pressure as before is established in the upper chamber. This measured flow is used to derive $R_{F}=Q_{L} / Q_{U}$. Equation 7 is then modified to give

$$
P_{U}=Q_{L} R_{P} /\left[\dot{R}_{F} C\left(R_{P}-1\right)\right] \text {. }
$$

Molecular drag and ion gages in the upper chamber are used to determine $R_{F}$. There is a random error in the determination of $R_{F}$ of the order of 0.18 . More importantly, there is an additional systematic uncertainty due to the two flowmeter measurements required. This effectively doubles the contribution of the flowmeter error in eq (8). In the NIST standard, $R_{F}$ differs from $R_{P}$ by 
less than 18 although this may be fortuitous since flux and pressure gradients of several percent are known to exist in the lower chamber.

The flow ratio cannot be directly measured for pressures lower than those that can be reliably generated by a measured flow into the upper chamber, which is $10^{-5} \mathrm{~Pa}$ for a 0.88 random uncertainty. However, since the system is clearly in the molecula: flow regime at these lower pressures, $R_{F}$ will be constant with decreasing pressure if the turbomolecular pump speed does not change with pressure. As described below we have indirect evidence that the pump speed does not change significantly down to $3 \times 10^{-8} \mathrm{~Pa}$. On one occasion we found that the turbomolecular pump speed had decreased over a period of weeks as the bearings deteriorated, causing a noticeable decrease in the pump rotor speed and in $R_{P}$.

\section{CALIBRATIONS AT HIGHER PRESSURES}

Because of the increasing deviations from conditions of molecular flow at pressures above $10^{-2} \mathrm{~Pa}$, calibrations in this range are performed against molecular drag gages which have been calibrated against the primary standard. Molecular drag gages are used because of their linearity, reproducibility, and precision in this pressure range. In brief, the molecular drag gage consists of a magnetically levitated rotor inside the vacuum chamber which is accelerated to about $400 \mathrm{~Hz}$. It is then allowed to rotate freely and the pressure is indicated by the deceleration of the rotor as gas molecules strike its surface (the molecular drag). There is an additional slowing due to eddy currents induced in the rotor by the magnets in the monitoring and suspension circuitry which is referred to as the residual drag.

Pressure is computed from the deceleration rate according to the following formula:

$$
P=(K / \sigma)(-\dot{w} / w-R . D .)
$$

where $w$ is the rotational frequency of the ball, $\dot{w} / w$ is the relative deceleration, $R$. D. is the residual drag, and $K$ is a constant which is a function of the ball density and diameter, the gas in use, and the temperature. The effective accommodation coefficient, $\sigma$, is determined when the MDG is calibrated. The orifice conductance and MDG are both sensitive to the molecular weight of the calibration gas. A thorough discussion of the theory of MDGs may be found in Refs. 3 and 4. A discussion of techniques for using the MDG may be found in Refs. 5 and 6 . 
MDG performance at pressures above $10^{-1} \mathrm{~Pa}$ is limited by nonlinearities arising from interactions between the gas surrounding the ball and the walls of the steel thimble which contains the ball in the vacuum chamber. The resulting changes may be empirically treated but NIST currently has no facility for evaluating this effect.

Comsa, et al. [7], have investigated the linearity of the MDG at pressures as high as $2.0 \mathrm{~Pa}$ using the primary vacuum standard (a static expansion system) at the Physikalisch-Technische Bundesanstalt (PTB). Their results show nonlinearities in the MDGs of 0.38 at $10^{-1} \mathrm{~Pa}$. The resulting errors in pressure are much smaller than those generated by the nonlinearities in the orifice conductance at these pressures, hence the use of the MDGs as transfer standards. As a general practice, we do not calibrate vacuum gages above $10^{-1} \mathrm{~Pa}$ using either the primary high vacuum standard or MDGs. The ultrasonic interferometer manometer is used at these higher pressures.

of greater concern is the increasing random noise in the residual drag of the MDG as the pressure is decreased toward $10^{-4} \mathrm{~Pa}$. We have investigated the errors in this range by calibrating IGs with both the orifice-flow system and with MDGs at pressures near $10^{-4} \mathrm{~Pa}$. Differences are less than 28 for IG measurements.

When using the MDGs as transfer standards, the flowmeter is simply treated as a gas source used to establish a steady flow of gas into the chamber. It is not important to know the flow rate, only that it is stable. The pressure in the chamber is measured by the MDGs, and the orifice serves to ensure a uniform pressure in the calibration chamber. The upper to lower chamber pressure ratio is computationally unimportant although a change would imply some degradation of the calibration system. The stability of the flow over the course of the measurement and a low base pressure are the most important qualities of the system in this configuration.

With a stable flow, the pressure is measured by the MDGs and readings are taken on the customer's ion gage. Because the MDG is a differential gage, the customer's gage reading must be corrected to reflect the fact that it reads total pressure while the MDG reads only the pressure above the base vacuum. This is accomplished by subtracting the base vacuum reading of the ion gage from the reading at the calibration pressure before the correction factor is computed. 
Each part of the calibration system must meet certain performance criteria to insure that the system is operating under optimum conditions. The chamber and orifice criteria are discussed above. The three remaining parts of the system are the molecular drag gages, the flowmeter, and the vacuum pumps. The criteria that have determined the design and selection of components are discussed below.

\section{Molecular Drag Gages}

Molecular drag gages are used as transfer standards to perform calibrations between $10^{-4}$ and $10^{-1} \mathrm{~Pa}$. Important characteristics of a transfer standard are long and short-term stability, ruggedness, and predictability. The molecular drag gage combines all of these characteristics. While there may be small effects on ball performance due to the vacuum thimble containing the ball and due to the controller, the major predictor of performance is the ball itself. The ball must contain some magnetic material and must be slightly aspherical in order that the spin and magnetic axes not align when the ball is rotating. It is the horizontal component of the magnetic field which produces the signal for the controller. However, if this asphericity is too large, the residual drag will have a large frequency dependence. This can be taken into account mathematically but may reduce accuracy at the lower pressures. In practice, commercially available steel ball bearings of diameter $4.5-4.76 \mathrm{~mm}$ may be used as rotors. These may be either shiny or etched and made of either normal steel or 400 series stainless steel.

The MDG performance is limited at the lowest pressures by the stability of the residual drag and its measurement (the offset correction) [8]. Factors affecting it are slow temperature changes, vibration, signal strength and timing circuitry errors. The factor having the largest impact on system design is the necessity to minimize vibrations. Temperature changes affect MDG performance as the dimensions of the ball change. The fact that the ball is contained in a vacuum helps to reduce the rate of temperature change.

The residual drag is equivalent to an apparent pressure reading of $10^{-4} \mathrm{~Pa}$ or more and its stability is important. Every effort is made to keep random errors no larger than $10^{-6} \mathrm{~Pa}$. At this level of stability, the MDG is capable of performance at the 18 level at pressures as low as $10^{-4} \mathrm{~Pa}$. 
The performance of these gages is discussed in the section on errors. With careful use, the calibration of the gage will change no more than 28 over a 2-year period.

\section{The Flowmeter}

\section{All letter references in this section are to figure 1.}

\section{The Gases}

Because the orifice conductance, the MDG constant $\mathrm{K}$, and the IG sensitivity are all dependent on the molecular mass of the calibration gas, gas purity is important. The gas composition in the chamber is routinely monitored with a residual gas analyzer to check for impurities. The calibration gases are used as purchased with no further purification and the purity levels have been more than adequate.

\section{Capacitance Diaphragm Gages}

The pressure in the reference reservoir is measured with capacitance diaphragm gages (C). Two, with different ranges, are used. Accuracy and long- term stability are the most important criteria. One of the CDGs is a $1.3 \mathrm{kPa}$ full-scale differential unit which uses the vacuum created by a small turbomolecular pump as its reference pressure. The other is a $133 \mathrm{kPa}$ absolute gage. The CDGs are calibrated against the NIST ultrasonic interferometer manometer which has an accuracy of $15 \mathrm{ppm} \pm 1.3 \times 10^{-2} \mathrm{~Pa}$.

A third CDG (D) is used to measure the pressure difference between the reference and working reservoirs. Short-term stability (20-30 minutes) is the most important criterion. This unit is only used to measure small pressure differences and is not calibrated.

\section{The Pistons}

The volume of the piston which moves into the working reservoir appears in eq (1) as dV. Therefore, dimensional stability and characterization are very important. We are using "wire gages" as pistons. These are readily available, well characterized, and carefully constructed cylinders of tungsten carbide. One of the pistons has a nominal diameter of 1 inch $(2.540 \mathrm{~cm}+$ $40 \mathrm{ppm},-0 \mathrm{ppm}$ ) and the other has a nominal diameter of $1 \mathrm{~cm}$ $(1.0000 \mathrm{~cm} \pm 51 \mathrm{ppm})$. They will be referred to as the inch and centimeter 
pistons, respectively. The pistons are coupled to stepping motors through bellows and twenty-turns-per-inch micrometer screws. There is about one-quarter turn backlash in the piston drive but this has no effect as the piston is always driven in the same direction during measurements.

The piston seals contain elastomers. In order to reduce gas leakage across these seals, the fill pressure is brought to both sides of each seal. Tests have indicated that the leakage across the seals under normal operating conditions contributes an error of no more than $0.01 \%$.

\section{The Piston Advance System}

A stepping motor turns a micrometer screw which drives the piston into the working reservoir and the rate at which the motor turns is controlled by the reading of the differential CDG between the working and reference reservoirs. The length the piston travels in a given number of turns enters directly into the throughput and pressure calculations as part of the displaced volume. Therefore, the threads of the screw must be linear and accurate. Checks of the micrometer screws have indicated that they are linear to \pm 0.001 inch.

As the piston is driven into the working reservoir, the elapsed time is measured with a resolution of 0.1 second and is displayed after each turn of the piston.

\section{$\underline{\text { Reservoirs }}$}

Thermal stability of the reference volume (B) is important so that its pressure does not change during a flow measurement (20-30 minutes). The working reservoirs (E) must be small in relation to the piston and both dimensionally and thermally stable. The nominal volumes of the working reservoirs are $39 \mathrm{~cm}^{3}$ and $32 \mathrm{~cm}^{3}$ for the 1-in and 1-cm pistons respectively (the nominal volumes displaced by the $1-$ in and $1-\mathrm{cm}$ pistons are 13 and $2 \mathrm{~cm}^{3}$ ). They are thermally insulated and the temperature is monitored. They are fabricated from stainless steel.

\section{Thermometers}

One thermometer on the flowneter measures the temperature of the working reservoirs. Accuracy is important so a calibrated quartz thermometer is used. A liquid-in-glass thermometer with a resolution of $0.05^{\circ} \mathrm{C}$ is used to monitor the chamber temperature. 
The flowmeter is thermally insulated but not temperature-controlled. It is insulated with polystyrene to protect it from short-term temperature fluctuations and insure internal uniformity. A second quartz thermometer is located inside the polystyrene at a different location from the first. The difference between the two temperatures is usually tens of millidegrees. The actual temperatures of the flowmeter and chamber are not important when the flowmeter is used simply as a pressure generator but they must be known when used in the primary standard configuration. Changes in the temperature difference between the reference and working reservoirs wll cause spurious differential pressure changes.

\section{Variable Leak Valve}

The gas from the working reservoir flows into the chamber through a commercially available, all-metal, variable leak valve (G). This valve enables us to have a large fill pressure, $P_{f m}$, and still introduce only a very small amount of gas into the chamber to achieve a given pressure. Large fill pressures can be more easily measured because of the characteristics of the CDGs and their calibrations, and they minimize the effects of outgassing. This valve must be dimensionally stable for stable flow and it is set the day before a calibration to stabilize mechanical drift which may change the conductance of this type of valve by as much as $10 \%$ overnight.

\section{Vacuum Pumps}

A small $\left(0.05 \mathrm{~m}^{3} \mathrm{~s}^{-1}\right)$ turbomolecular pump backed with a mechanical pump is used to evacuate the flowmeter reservoirs and to provide a reference vacuum for the $1.3 \cdot \mathrm{kPa} C D G$ on the reference reservoir. A second mechanical pump serves as a roughing pump for the ballast volume and flowmeter reservoirs. A larger turbomolecular pump $(J)$ exhausts the chamber. Its speed must be constant over long periods of time in order to make meaningful measurements. The pump speed must also be high enough to ensure a large pressure ratio across the orifice and a very low base vacuum (two orders of magnitude below the lowest calibration pressure for both MDGs and IGs if possible). The pump in use has a nominal pumping speed of $0.5 \mathrm{~m}^{3} \mathrm{~s}^{-1}$ for $\mathrm{N}_{2}$ gas. The turbomolecular pump is backed by a molecular-sieve trapped mechanical pump. An additional requirement is that the pump be free from mechanical vibration in order that the stability of the MDG readings not be compromised. We have 
found turbomolecular pumps to be satisfactory if the MDGs are mounted with care.

\section{OPERATIONAL PROCEDURES FOR CALIBRATION USING THE NIST HIGH VACUUM STANDARD}

This section describes in some detail the operation of the orifice-flow standard. Users are referred to Ref. 6 for MDG operating procedures.

There are two flowmeters of similar design at NIST and either may be used with the orifice-flow standard. It is also possible to use either flowmeter with the primary leak standard. However, there is only one vacuum calibration chamber with an orifice of the design described above. The chamber has eight ports of which one is part of a by-pass manifold between chamber halves and one is occupied by a residual gas analyzer. This leaves six ports for gages under test and transfer standards. Care must be taken that ion gages sharing ports do not interact by having ions generated in one gage collected at the other. This is generally accomplished by avoiding line of sight connections between ionization gages. Within these limitations, the number of gages that may be calibrated at one time is limited only by gage geometry and operator preference.

As discussed earlier, the IG calibrations fall naturally into three groups :

Table II. Primary Standard Configuration Used for Calibrations

\begin{tabular}{lll}
$\frac{\text { Pressure }}{\mathrm{Pa}}$ & $\begin{array}{c}\text { Flow in Which } \\
\text { Chamber }\end{array}$ & $\begin{array}{c}\text { Piston } \\
\text { Diameter }\end{array}$ \\
\cline { 2 - 3 } $10^{-6}$ to $10^{-5}$ & Lower & One Centimeter \\
$10^{-5}$ to $10^{-4}$ & Upper & One Centimeter \\
$>10^{-4}$ & Upper & One Inch or MDGs \\
\hline
\end{tabular}

MDGs are calibrated with the flow into the upper chamber using the 1-in diameter piston. These calibrations are procedurally like the IG calibrations between $10^{-5}$ and $10^{-4} \mathrm{~Pa}$. The calibration is performed at only one pressure $\left(5 \times 10^{-3} \mathrm{~Pa}\right)$ which represents a compromise between the upper limits of the orifice conductance linearity and the lower limit of acceptable MDG performance. The MDGs remain linear between $10^{-4}$ and $10^{-1} \mathrm{~Pa}$ but the random scatter in the residual drag becomes a problem near $10^{-4} \mathrm{~Pa}$ if performance at the 18 level is desired. 


\section{INSTALLATION AND PREPARATION OF GAGES}

\section{Bake-Out}

Each venting of the system must be followed by a complete baking of the chamber and inlet lines. The chamber is designed to be baked at temperatures up to $250^{\circ} \mathrm{C}$. The gas pison flowmeter may not be baked because of the use of elastomer seals for the pistons but as much of the gas line to the chamber as possible should be baked. At present, only the chamber and the inlet line between the variable leak valve and the chamber are baked. The flowmeter upstream from the variable leak valve is maintained at high enough pressures to ensure viscous flow so outgassing and backstreaming during the bake are not so critical.

The MDG balls are cleaned in alcohol and acetone and dried in a stream of pure nitrogen gas. The thimbles should be degreased if they have been exposed to contaminants.

Once the gages have been installed on the chamber with metal-gasketed seals, high temperature leads are attached between all IGs and ion gage controllers. The IGs are operated during the bake-out. Suspension heads must be removed from the MDGs. The turbomolecular pump and its mechanical roughing pump are started and the system is checked for leaks: Once it has been ascertained that the system is leak-tight, the chamber is evacuated with the roughing and turbomolecular pumps and the ion gages are turned on. The IGs should be set for the biases and emission currents at which they will be calibrated. The oven is carefully lowered over the entire chamber and the oven controller, safety switch and thermocouple connected. A flow of argon gas generating about $10^{-4} \mathrm{~Pa}\left(10^{-6}\right.$ Torr $)$ as monitored by an IG in the chamber is established through the inlet line into the chamber. Because of the small conductance of the inlet line, this will maintain viscous flow in the inlet line and across the variable leak valve to prevent backstreaming of contaminants.

The oven controller may now be turned on to increase the temperature slowly. It should take at least a day to reach $250^{\circ} \mathrm{C}$. Slow heating is needed because the temperature must remain uniform so that the upper and lower chamber flanges do not differentially expand with respect to the center plate between them. The temperature may be monitored with the thermocouple. When the chamber is at maximum temperature, the inlet line is heated by a bank of low-voltage transformers passing equal currents of approximately $60 \mathrm{~A}$ from the center of the inlet line through each half. This configuration is used 
because the inlet line is grounded at the flowmeter and at the chamber. The inlet line should sizzle when water is dropped on it. In addition, the heater on the turbomolecular pump should be started.

The oven should remain at temperature for at least 8 hours. Then, the controller may be set to decrease the temperature slowly. The inlet line should be cooled slowly and the turbomolecular pump heater switched off. The goal is keep the temperatures of all components as uniform as possible so that impurities do not condense in cold spots.

After the external oven walls are cool, the argon flow is stopped and the oven may be removed. When the MDG thimbles have cooled to room temperature, the suspension heads may be attached, and the balls levitated and accelerated. The pick-up signals of the MDGs should be checked and the signal scatters monitored. If needed, the suspension head may be removed after the ball is braked to a stop and the ball remagnetized to improve the pick-up signal strength. This completes the baking procedure.

\section{Degassing}

The IGs are normally degassed by operating them during the baking of the chamber. This has served very well. On some occasions, it may be desirable to further degas a specific IG after baking by wrapping it in glass wool building insulation and operating it overnight. Electron bombardment or resistance heating of the grid is not used.

\section{THE DAY PRIOR TO THE CALIBRATION}

Preparations for calibration against the NIST Primary High Vacuum Standard begin the day before the actual calibration. Several procedures must be completed in preparation - the MDGs must be spun up, the IG voltages and currents should be checked, the flowmeter pistons must be positioned, and the leak valve must be set for the proper flow rate.

The MDG balls must be spun up if they are to be used. This is done the day before in order that they may dissipate the heat produced by the acceleration process. If the ball has been at rest, one must wait several hours (5-7) before the effect of the cooling is less than the equivalent of $1 \times 10^{-6} \mathrm{~Pa}$, so it is essential that this be done the day before calibrations.

If IGs are to be used, the filament and grid biases of those gages on NIST-built controllers should be adjusted as should the emission currents. This is straightforward. The emission currents of customers' gages should be 
checked and adjusted if necessary and the zeros of the electrometers should be set by mechanical adjustment on a high-range scale and electrical adjustment at low-range scale readings after removing the collector lead.

For pressures at the low end of the range $\left(<10^{-4} \mathrm{~Pa}\right)$, the 1 -cm diameter piston will be used. The 1 -in diameter piston covers the higher end $\left(>10^{-4}\right.$ Pa) (see table II). The piston not in use should be left at the end of its travel to make the volume of the working reservoir as small as possible. The piston to be used should be placed at the top of its travel and then advanced slightly to eliminate backlash.

The leak valve must be set the night before a calibration to stabilize mechanical drift. The flowmeter performs most reliably when the piston takes about 1000 seconds to travel 1-in. All leak valve adjustments should be made in the direction of increasing conductance as the valve has substantial backlash.

In general, the system should be left overnight with the flowmeter and chamber evacuated and the orifice plate up. If very low pressures are to be generated (near or even below $1 \times 10^{-6} \mathrm{~Pa}$ ), it may be advisable to leave the orifice plate down overnight for maximum stability in the base vacuum.

\section{THE MORNING OF THE CALIBRATION}

The first order of business is to check the base readings of the IGs to be sure that the system is at an appropriate base pressure. If so, the orifice plate should be gently lowered if it is up and the time noted. Then, the IG voltages and currents should be rechecked. The chamber temperature should be noted and the MDGs set up for the day. This will involve entering the date, run number, gas and ball parameters (molecular weight, viscosity, diameter, density and temperature of $298.15 \mathrm{~K}$ for a second generation gage), an effective accommodation coefficient ( 1 for any second generation gage to be calibrated), timing interval of 30 in the second generation units, etc., as appropriate.

After the gage readings have stabllized (about $45 \mathrm{~min}$ after lowering the orifice plate), the base readings of the IGs and MDGs should be checked for stability. The MDG readings should be stable to better than $\pm 1 \times 10^{-6} \mathrm{~Pa}$. Offsets should be read for the MDGs and the base readings for the IGs should be taken. These offsets should be entered into the MDG controllers and the resulting MDG readings should be observed to be sure that they vary about zero 
$\mathrm{Pa}$. Then, gas may be introduced into the appropriate half of the chamber from the flowmeter.

Depending on the calibrations to be done, the flowmeter may be used to generate a known flow of gas or it may be used simply to establish a steady flow. The second case is a subset of the first and will be discussed later.

\section{MEASURED FLOW TO UPPER CHAMBER \\ Order of Pressure Generation}

Pressures to be measured should be established sequentially from the lowest to the highest for each gas. This ensures that the elastomer seals and any IGs on the system will not absorb gas at higher pressures and desorb at subsequent lower pressures. This may not always be possible from day to day but in no case should a higher pressure be run before a lower one within a day. The only exception is to evacuate the chamber in order to check the residual drag of an MDG.

\section{Establishing a Pressure}

The gas flow is directed into the upper chamber for the calibration of all MDGs and the calibration of IGs at pressure above $10^{-5} \mathrm{~Pa}$. Gas is introduced from the compressed gas cylinder into the ballast volume and reservoirs while the test or monitoring gages are observed. When the desired calibration pressure has been reached, the inflow is halted. The ballast volume now serves as the source of gas. The fill pressure may be adjusted to achieve the calibration pressure. At this point, the gas should be allowed to flow for about 45 minutes while the elastomer seals in the working reservoir absorb gas.

During this time, the operator should check that the necessary parameters have been entered into the MDG controllers and check the IG operating parameters.

Flowmeter operation is initiated by closing the valve which isolates the reference reservoir. The valve should be closed slowly because there is the possibility that gas will be driven into the reference reservoir by the valve, raising the pressure. Once the valve is closed, the fill pressure is read with the appropriate CDG and recorded. At the same time, the chamber and working reservoir temperatures are read and recorded.

Next, the valve is closed which removes the ballast volume from the system. The differential CDG is monitored while this valve is closed and the 
final reading should be slightly positive. Once the valve is closed, the pressure in the working reservoir will start to fall because gas is flowing out of the reservoir into the chamber. Any time before the differential pressure reading becomes negative, piston travel should be enabled. The piston only travels when the reading is negative and overshoots slightly on each step. There is provision to choose between proportional and on-off control of the piston advance.

The elapsed time for each turn of the piston is monitored and displayed. This display is locked for one-half of each turn to enable the operator to note both it and the reservoir temperature as read by the quartz thermometer. The mid-point of all gage readings should occur half way through the piston travel (turn number 10). The IGs are read once before turn 10 and again in reverse order after turn 10 in order to average the effects of any pressure drift. The MDG readings should be started at times appropriate to the timing algorithm of the controller so that the mid-point of the readings occurs at the tenth turn.

After 1-in of piston travel (20 turns), piston travel is stopped and the working reservoir is reconnected to the ballast volume and the fill pressure is read as are the chamber and reservoir temperatures. Then the piston is driven out, the reference reservoir valve is opened, and the system is either pumped out or adjusted for the next series of measurements. If a new pressure is established, the operator must wait another 45 minutes for gas sorbtion in the elastomer seals to equilibrate.

\section{MEASURED FLOW TO LOWER CHAMBER}

To calibrate ion gages between $10^{-6}$ and $10^{-5} \mathrm{~Pa}$, the gas flow is directed into the lower chamber. The operation of the flowmeter is as outlined above. The 1 -cm piston is normally used in this pressure region. Data are taken as above, the only difference being in the data analysis. The ratio of flow in the lower chamber to that in the upper chamber, $R_{F}$, for a given pressure must be determined and eq ( 8 ) used instead of eq (7).

\section{STEADY FLOW GENERATOR}

For the calibration of IGs above $1 \times 10^{-4} \mathrm{~Pa}$, the flowmeter is used only to generate a steady flow. In this case, the piston is not used. Gas is admitted into the ballast volume until the desired calibration pressure is reached. Gas from the ballast volume is allowed to leak into the upper 
chamber and the gages are monitored until the readings are steady. At this time the gages are read: MDG readings are started, the IGs are read once, and then the IGs are read in reverse order. The analysis of the gage readings is described below with the exception that a group of MDGs is used to measure the chamber pressure. MDGs which are used as transfer standards should have the appropriate calibration parameters entered before the offset data are taken.

\section{SHUTTING DOWN}

After the last run of the day, the flowmeter should be evacuated with the mechanical pump and the small turbomolecular pump. The MDG readings at base vacuum should be checked with the orifice in place to evaluate errors caused by possible drifts in the residual drag. Then, the orifice plate should be raised.

\section{VENTING THE SYSTEM}

Several precautions should be taken before the system is vented to remove customers' gages or for any other reason. All IG and residual gas anaylzers must be turned off. The MDG drive must be disabled. The suspension heads may be left on or not until they must be removed for baking. If they are to be removed, the balls must first be stopped using the controllers (and an oscilloscope or spectrum anaylzer to monitor their rotational frequencies if necessary) and lowered into their thimbles. The residual gas analyzer must be isolated behind a closed valve. The turbomolecular pump is stopped and its mechanical pump vented.

The system pressure is increased to slightly above one atmosphere with argon or dry. nitrogen. The system is then vented.

\section{DATA ANALYSIS}

Three types of data may be gathered in the course of a calibration. The first are the data pertaining to the flowmeter which will be used to calculate the pressure in the upper chamber. The second are the MDG readings and the third are the IG readings. The way in which the system is being used and the instruments being calibrated will determine which types of data are recorded. Concerning the first (the flowmeter), the operator should have the following numbers available:

The fill pressure before and after the run, $P_{f m}$.

The chamber temperature before and after the run, $\mathrm{T}_{\mathrm{ch}}$. 
The reference reservoir temperature before and after the run, $\mathrm{T}_{\mathrm{fm}}$. When the flow is into the upper chamber, the formula used to calculate the pressure is

$$
P_{U}=(Q / C)\left(R_{P}\right) /\left(R_{P}-1\right)
$$

where $Q$ is the throughput into the upper chamber given by

$$
Q=P_{f m}(d V / d t)\left(T_{c h} / T_{f m}\right)
$$

and $C$ is the conductance of the orifice given by

$$
\mathrm{C}=\mathrm{C}^{*}\left(\mathrm{~T}_{\mathrm{ch}} / 298.15 \mathrm{~K}\right)^{1 / 2} \text {. }
$$

$P_{f m}$ is the average fill pressure which is measured in terms of the output of the CDG (i.e., in volts). The NIST calibration coefficents of the CDG are used to convert the average of the before and after readings into Torr and this is converted to pascals using the factor 1 Torr $=133.322 \mathrm{~Pa}$. dV is the volume of the piston which was driven into the working reservoir. The values are $1.9949 \mathrm{~cm}^{3}$ for the $1-\mathrm{cm}$ piston and $12.870 \mathrm{~cm}^{3}$ for the 1 -in piston. dt is the total time elapsed for the piston travel (the first reading minus the twenty-first reading). $C$ is the temperature-corrected value of the conductance of the orifice and $C^{*}$ is the value of the conductance at $298.15 \mathrm{~K}$ (Appendix $C$ ). $\quad R_{P}$ is determined experimentally and checked periodically. Its value depends on the gas in use and the performance of the turbomolecular pump.

When the flowmeter is used with the flow into the lower chamber, $Q^{*}$ is calculated as above and then divided by $R_{F}$, the lower to upper chamber flow ratio. This gives the effective throughput that would be required to generate the calibration pressure with the flow into the upper chamber. The final form of the equation for the throughput becomes

$$
\mathrm{Q}=\mathrm{P}_{\mathrm{fm}}(\mathrm{dV} / \mathrm{dt})\left(\mathrm{T}_{\mathrm{ch}} / \mathrm{T}_{\mathrm{ch}}\right) / \mathrm{R}_{\mathrm{F}} \text {. }
$$

For ion gages read with commercial or customer controllers, the generated pressure should be divided by the.IG reading minus the IG reading at base vacuum to obtain a calibration factor:

Cal. Factor $=$ Pressure drop/(IG reading - IG reading at base vacuum) Attention should be paid that all readings are in the same units of pressure (usually Torr).

Ion gage readings taken on NIST-built controllers require more work to reduce them to gage sensitivies. The data acquired at each pressure consist of the collector current and the voltage drop across a known resistor due to the emission current. Comparable data are also taken at base vacuum. The following equations are used to calculate gage sensitivity, $\mathrm{S}$ :

$$
I_{e}=V_{e} / R_{c}
$$




$$
\begin{gathered}
I_{c}=I_{c}^{\prime} E \\
S=\left(I_{c}-I_{c o}\right) /\left(I_{\theta} P\right)
\end{gathered}
$$

where $R_{c}$ is a resistor specific to the controller and the emission current range, $V_{\theta}$ is the voltage drop across $R_{c}, I_{\theta}$ is the emission current, $I_{c}^{\prime}$ is the measured collector current, $\mathrm{E}$ is a range factor for the electrometer and $\mathrm{P}$ is the generated pressure. The subscript "o" refers to readings at base vacuum.

MDG readings are the average of 10 readings taken about the tenth turn of the piston. The calibration coefficient is determined by dividing the generated pressure by the MDG reading. The effective accommodation coefficient is determined by dividing the MDG reading by the generated pressure.

\section{ASSESSMENT OF UNCERTAINTIES}

\section{SYSTEMATIC ERRORS}

In addition to the errors already discussed in Appendix $C$ regarding the conductance calculation and the measurement of the pressure and flow ratios, $R_{P}$ and $R_{F}$, several other possible sources of error must be taken into account.

\section{Pressure Gradients}

A high degree of pressure uniformity from port to port in the upper chamber has been demonstrated by establishing a nitrogen flow to generate a pressure of about $10^{-3} \mathrm{~Pa}$ in the upper chamber. The pressure was measured by four ion gages which were well distributed about the upper chamber. After recording the gage readings, the orifice plate was raised and the flow was increased by a factor of about 15 to establish the same pressure. The relative gage readings with the orifice plate raised agreed to within 0.18 with the reading obtained with the orifice plate lowered. Since nonuniformity due to axial asymmetry of the flow would be proportional to the flow rate required to generate a specified pressure, the results indicated any such nonuniformity to be less than 0.018 in normal operation with the orifice plate lowered.

The upper chamber pressure will have a vertical perturbation due to the net flow of molecules between the gas inlet and the orifice. This will have two contributions, one due to the molecules exiting through the orifice and not being scattered back, and the second due to the molecules entering from the inlet. The first contribution is reasonably straightforward to calculate 
since the orifice is an ideal sink. This contribution will decrease the pressure at the gage ports from that given in eq (7) by a factor of 0.99956 .

The second cantribution is more difficult to calculate because the scattering of the inlet flow produces a diffuse source and it will take several collisions before the effects of the initial nonuniformity are negligible. However, this contribution is somewhat smaller than the first, but of the opposite sign. The sum of these two contributions results in a condition in which the pressure at the gage ports is slightly less than at the orifice so that the net flow of gas is from a region of lower pressure to one of higher pressure, an entirely possible result in the molecular flow regime.

\section{Mounting of the Orifice Plate}

Another small error is the perturbation of the calculated conductance caused by the mounting of the orifice plate. The orifice plate is mounted in the wall between the two chambers with a short duct, $12.7 \mathrm{~cm}$ in diameter and $1.27 \mathrm{~cm}$ long, between it and the lower chamber. The probability of transmission to the lower chamber of molecules exiting the orifice is estimated to be $0.9997 \pm 0.0001$. This effectively increases the pressure in the upper chamber by the factor of 1.0003, offsetting the effect at the gage port of the small vertical pressure gradient previously discussed.

We estimate that 0.0038 is a generous upper bound on the uncertainties caused by the combined upper chamber pressure gradients and the mounting configuration of the orifice plate.

\section{High Pressure Nonlinearities}

The calculation of the orifice conductance assumes an absence of molecule-molecule collisions. The number of such collisions increases with pressure, with a corresponding increase in the error of the conductance calculation. We have chosen at this time not to attempt to correct for this effect but rather to restrict the upper pressure limit of the standard to keep this error within reasonable bounds. The error due to non-molecular flow conditions amounts to 0.18 at about $8.5 \times 10^{-3} \mathrm{~Pa}$ for $\mathrm{N}_{2}$ and at about $2.5 \times 10^{-2}$ $\mathrm{Pa}$ for He, and increases linearly with pressure.

The orifice-flow standard was operated above the molecular flow range to assess the total nonlinearity of the system at "high" pressures. MDGs were used as the standards in this case as their nonlinearity is known and is smaller than the nonlinearity in the orifice conductance (Appendix $C$ ). The 
results are based on the readings of 12 MDGs taken over a period of 4 days and are summarized in table III below. Total deviations are expressed as the mean difference between the pressure indicated by the MDGs and pressure generated by the high vacuum standard \pm three times the standard deviation of the MDG readings.

Table III. Primary Standard Nonlinearities

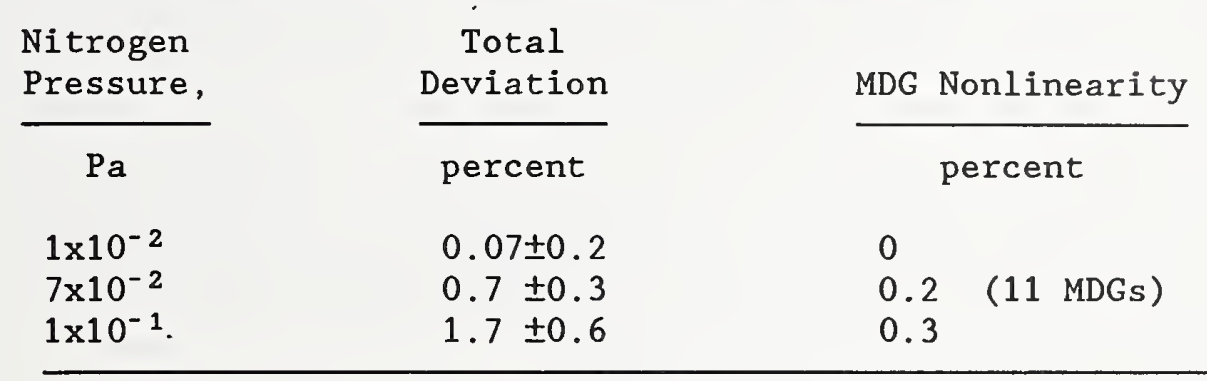

\section{Temperature}

The average temperature of the gas molecules is determined by the average temperature of the chamber walls, which is known with an uncertainty of $0.3 \mathrm{~K}$ in the absence of heat sources, notably ion gages. The normal temperature is 296 to $298 \mathrm{~K}$. Ion gages are heat sources and, depending on the number of gages and whether they are tubulated or immersed in the chamber, this uncertainty in the chamber temperature could be as much as an order of magnitude larger in extreme cases. This will contribute an uncertainty to the pressure varying from 0.05 to $0.5 \%$. This does not include uncertainties in the thermal transpiration corrections for ion gages being calibrated.

\section{Flow Rate Errors}

The uncertainty of the flowmeter [1] is dominated by the uncertainty of the capacitance diaphragm gages (CDGs) used to measure pressures. The uncertainty of the CDGs is based on observed calibration shifts of the CDGs used in the flowmeter and our experience with the long-term stability of a larger group of CDGs [9]. The estimated total systematic uncertainties of the flowtheter are listed in table IV.

\section{Changes in Pump Speed}

As discussed earlier, the pressure and flow ratios can be reliably measured only at higher pressures and their use in eqs [7] and [8] at lower 
pressures assumes that pump speed does not change with decreasing pressure. Any change in the pump speed will cause errors in the calculated pressure, with corresponding errors in the sensitivity of any gage calibrated. In particular, a decrease in pump speed, with decreasing pressure, will cause an apparent increase in gage sensitivity. This will be particularly true for measurements made with gas flow into the lower chamber since the pressures calculated from eq (8) depend directly on $R_{F}$, which depends directly on the pump speed. A constant measured gage sensitivity implies that either the gage sensitivity and pump speed are both constant, or that both change with pressure in a manner such that the changes exactly cancel. Neither case can be proven, but it is unlikely that different gages will have the same nonlinearities, particularly if the gages are of different designs, so, as more gages are found to have constant measured sensitivities, the second possibility becomes increasingly unlikely.

The low pressure ion gage sensitivities presented in figure 4 for different gages calibrated over a year's time can be used to establish an upper bound on possible pump speed changes. The results include random uncertainties in both the gages and the standard. The data in figure 4b) and 4c) were for gages calibrated with flow into the lower changer and their sensitivities show a maximum change (in all cases a decrease) of 28 in going from $10^{-4}$ to $10^{-6} \mathrm{~Pa}$. In a second experiment, data were taken on four different type of ion gages at pressures from $3 \times 10^{-6}$ to $10^{-4} \mathrm{~Pa}$ using flow into both the upper and lower chambers. The difference in the sensitivities determined by the two methods over a period of up to 5 days was between -1 and +18 .

Another method of assessing pump speed changes is to look for trends in ion gage calibration data. Sixteen ion gages were calibrated by directing the flowmeter into the lower chamber at pressures between $3 \times 10^{-8}$ and $4 \times 10^{-3} \mathrm{~Pa}$ and the resulting data were fit to an equation of the form $S=A+B(\log P)$, where $S$ is the gage sensitivity and $P$ is the generated pressure [10]. The slopes (B) of these 16 equations varied from -2.5 to $3.9 \%$ per decade. If the individual coefficient are weighted by their inverse variances, the average value of $B$ for the 16 gages is less than $1 \%$ per decade.

Any assessment of the pump speed will, of necessity, involve random errors due to the gages involved. Based on these data and the discussion of random errors below, we have set the error due to pump speed variation at $2.5 \%$ per decade below $10^{-5} \mathrm{~Pa}$. 
Upper bounds on the random errors can be set by evaluating the variation of repeated gage calibrations. These numbers will, of course, include the random errors of the gages as well as those of the standard.

A measure of the short-term repeatability at higher pressures can be obtained from four repeated calibrations of six different MDGs with $\mathrm{N}_{2}$ at $4.9 \times 10^{-3} \mathrm{~Pa}$. In this case, the calibrations were made over a period of 8 hours. The pooled standard deviation of the effective accommodation coefficients of the six gages was 0.00026 (the nominal effective accommodation coefficient is 1.0 ) with no significant difference in the random errors associated with any gage.

$\dot{A}$ second experiment was performed to check longer-term performance of the system. Twelve MDGs were mounted on the system and were calibrated in nitrogen at pressures ranging from $10^{-4}$ to $10^{-1} \mathrm{~Pa}$. Each MDG was calibrated two to six times at each pressure over a 5-day period. The pooled standard deviations of the effective accommodation coefficients were 0.0011 at $5 \times 10^{-3}$ $\mathrm{Pa}$ and 0.0017 at $1 \times 10^{-4} \mathrm{~Pa}$.

Similar results were obtained when repeated calibrations of 10 MDGs were done with argon at pressures ranging from $5 \times 10^{-4} \mathrm{~Pa}$ to $3 \times 10^{-2} \mathrm{~Pa}$. In this case, three to five different calibration series were performed at each pressure, each series taking place on a different day and involving a complete calibration cycle, starting with the vacuum chamber and flowmeter at base vacuum and the orifice plate raised above the gallium-filled groove. The data from two of the MDGs were eliminated because of clearly excessive random errors in the gages. The pooled standard deviations of the remaining eight gages were 0.0010 at $3 \times 10^{-2} \mathrm{~Pa}, 0.0008$ at $7 \times 10^{-3} \mathrm{~Pa}, 0.0012$ at $3 \times 10^{-3} \mathrm{~Pa}$, and 0.0041 at $5 \times 10^{-4} \mathrm{~Pa}$.

At the lowest pressures the above results are probably dominated by the short-term random errors of the MDGs, and MDG data at yet lower pressures will not be useful in assessing random errors of the standard. Therefore, we must rely on ion gage data at lower pressures.

As a measure of the random errors at low pressure, short-term repeatability data were obtained with three calibrations for a tubulated, tungsten-filament Bayard-Alpert gage made over a period of several hours. In this case separate flowmeter measurements were made for each calibration. At $2 \times 10^{-4} \mathrm{~Pa}$ the calibrations differed by a maximum of 0.18 , and at $2 \times 10^{-5} \mathrm{~Pa}$ by 0.028 . 
A more realistic assessment of the random errors can be obtained from calibrations repeated on different days. For flow into the upper chamber we expect that errors at the lowest pressures will be dominated by random flowmeter errors. The data in figure 4a) are typical of that for ion gages calibrated in this manner, indicating random variations equivalent to $\pm 5 \times 10^{-8}$ $\mathrm{Pa}$. This is consistent with the random errors shown for a different gage, again calibrated with the flow into the upper chamber, shown in figure 4d). Where calibrations of the same gages have been performed with flow into the lower chamber, and repeated flow into the upper chamber, the results agree to within $1-2 \%$. Examples of such data are. shown in figures $4 \mathrm{~b}$ ) and $4 \mathrm{c}$ ). These data indicate an upper bound on the random errors of 28 down to pressures where the flowmeter random errors will again dominate. For flow into the lower chamber we expect that these errors will exceed 28 at $1 \times 10^{-7} \mathrm{~Pa}$.

An additional estimate of the random errors at low pressures is obtained by examining the results of calibrating sixteen ion gages over the pressure range $3 \times 10^{-8}$ to $4 \times 10^{-3} \mathrm{~Pa}$ by flowing gas into the lower chamber [10]. Repeated calibrations for most of the gages differed by less than $\pm 2.5 \%$ and linear fits of these calibration data had standard deviation of the residuals between 0.26 and $3.5 \%$ with an average standard deviation of $1.95 \%$.

Based on the data above, we have adopted \pm 2.58 as the upper bound on random errors of the standard with flow into the lower chamber to $10^{-6} \mathrm{~Pa}$.

\section{SUMMARY OF ERRORS}

The component errors previously discussed are summarized in table IV for nitrogen at four different pressures. The uncertainties at the highest pressure designated "molecular scattering" are due to the high pressure nonlinearities in the conductance of the orifice. The effects due to pressure gradients in the upper chamber and orifice mounting have been left out as negligible. Errors at the lowest pressure have been assessed on the basis of flow into the lower chamber. The flow ratio contribution includes random errors and a systematic contribution for the additional flowmeter measurement needed. The uncertainty due to changes in the assumed pumping speed is based on the observed bounds of systematic changes in measured gage sensitivities. This uncertainty is not applicable at higher pressures because with flow into the upper chamber the effects of changing pump speed are greatly reduced. The uncertainty for temperature errors has been somewhat arbitrarily doubled from the minimum expected value. 
The tabulated random errors are upper bounds based on repeated MDG calibrations with nitrogen and argon. These included the random errors of the standard, flowmeter and gages. The value at $10^{-4} \mathrm{~Pa}$ is based on three times the short-term deviations observed in ion gage calibrations at this pressure. We expect that longer term random changes, due to orifice plate sealing and flowmeter seals leakage, are probably no different from those included in the higher pressure MDG data.

Random errors are not tabulated at $10^{-6} \mathrm{~Pa}$ because they are included in the determination of the pump speed uncertainty.

Assessment of errors in some cases is hampered by the limited data available. Therefore, we must regard these results as tentative at this time. As we gain more data and experience with the operation of this system, we expect the uncertainties to change. In particular, we expect to reduce the uncertainties due to the flowmeter by maintaining tighter calibration control over the CDGs.

TABLE IV. Uncertainties of the NIST High Vacuum Standard with Nitrogen

\begin{tabular}{|c|c|c|c|c|}
\hline & \multicolumn{4}{|c|}{ Pressure, $\mathrm{Pa}$} \\
\hline & $10^{-1}$ & $10^{-2}$ & $10^{-4}$ & $10^{-6}$ \\
\hline Systematic Contributions & 0.18 & 01.8 & 0.18 & 0.18 \\
\hline Orifice Conductance $(\&)$ & 0.18 & 0.18 & 0.18 & 0.18 \\
\hline Molecular Scattering ( 8$)$ & 1.2 & 0.12 & - & - \\
\hline Flow Rate $\left(\frac{8}{8}\right)$ & 0.82 & 0.82 & 0.82 & 2.00 \\
\hline Pressure Ratio ( 8 ) & 0.04 & 0.04 & 0.04 & 0.04 \\
\hline Flow Ratio ( 8 ) & - & - & - & 0.90 \\
\hline Assumed Pump Speed $(q)$ & - & - & - & 2.5 \\
\hline Temperature $(8)$ & 0.1 & 0.1 & 0.1 & 0.1 \\
\hline Total Systematic ( 8$)$ & 2.34 & 1.26 & 1.14 & 5.72 \\
\hline Random Errors (3 S.D., 8) & 0.21 & 0.30 & 0.30 & - \\
\hline Total ( 8 ) & 2.6 & 1.6 & 1.4 & 5.7 \\
\hline
\end{tabular}

We have chosen to linearly sum the systematic errors and three times the random errors as a worst-case estimate. If the individual systematic errors were combined using the square root of the sum of the squares and three times the random errors were linearly added, the results would be $1.68 \%$ at $10^{-1} \mathrm{~Pa}$, 1.158 at $10^{-2} \mathrm{~Pa}, 1.158$ at $10^{-4} \mathrm{~Pa}$, and 3.338 at $10^{-6} \mathrm{~Pa}$. 


\section{VI, QUALITY CONTROL}

The determination of systematic and random errors in a primary standard is but the first step in characterizing its performance. By its very nature, a primary standard is difficult to monitor over long periods of time and varlous laboratories have developed several methods of doing this. Some of these are the maintenance of additional primary standards, interlaboratory comparisons of primary standards of the same or different designs, and the maintenance of a bank of check standards. We have adopted all three of these me thods.

\section{COMPARISONS AGAINST ADDITIONAL NIST PRIMARY STANDARDS}

The original primary high vacuum standard in use before 1984 [11] was suitable only for the direct calibration of early molecular drag gages. It was based on the integrating principle of the MDG rotor and the integrating capabilities of the MDG controller, and was operated by exhausting a known volume of gas into the chamber ("gas burst" method). The MDGs respond not to pressure per se but to molecular flux and the deceleration experienced by the gages was due to the total number of molecules striking the ball surface. The calibration was a two step procedure and gave reproducible calibration factors over time.

Upon completion of the orifice-flow standard, it was compared with the 3 burst nethod described above using 5 MDGs as transfer standards. The sypical difference between the two methods was $0.1 \%$ and the worst difference was 0.5. This case occurred using the small $(1 \mathrm{~cm})$ piston in the flowmeter. We have subsequently modified the piston-drive circuit to allow for both proportional and on-off control. A major advantage of the flowmeter is that it may be used to calibrate IGs as well as MDGs since the pressure generated in the chamber is calculated directly and can be kept constant.

A eecond flowmeter has been constructed which operates on the same principle as the flrst [1]. The primary differences between them lie in the design of the piston seals and improved fill pressure measurement capability in the second floweter. The second flowmeter does not use elastomer seals but hydraullcally translates the piston motion to a bellows which is part of the working reservoir. This second flowmeter is completely bakeable. The orlginal floweter has only two CDGs for measuring the fill pressure - 1.3 and $133 \mathrm{kPe}$ (10 and 1000 Torr) full-scale. The second flowmeter has three CDGs $0.13,1.3$ and $133 \mathrm{kPa}(1,10$, and 1000 Torr - and a force-balanced quartz 
Bourdon gage. Some initial work has been done to compare the two flowmeters using both standard leaks and MDGs as transfer standards. The leak work has been done at low flow rates while the MDG work has of necessity been done at much higher flow rates. Eleven MDGs were calibrated on both flowmeters between $10^{-4}$ and $10^{-1} \mathrm{~Pa}$ over a 10-day period. The differences in the calibrations on the two flowmeters ranged from 0 to $0.5 \%$. For eight of the gages, the differences were within three standard deviations of zero. The leak data showed differences of $<18$ at flow rates above $10^{-11} \mathrm{~mol} \mathrm{~s} \mathrm{~s}^{-1}$

\section{INTERNATIONAL COMPARISONS}

Two calibrated MDG balls were sent to the Physikalisch-Technische Bundesanstalt (PTB) and the National Physical Laboratory in England (NPL) for comparison against the static expansion standards at those facilities. The success of these comparisons was limited by instabilities in the balls. The first ball gave very promising results - the results from all three laboratories were within 18 of each other and the first and last calibrations, done at NIST, differed by less than 18. The second ball was very unstable. The results are given in table $\mathrm{V}$ below. The instability was traced to changes in the residual drag, not to ball surface changes. Subsequent calibrations at NIST have indicated that neither ball was particularly stable.

\section{TABLE V. Results of First International Intercomparison}

\begin{tabular}{lcc} 
Laboratory & \multicolumn{2}{c}{$\begin{array}{c}\text { Difference from } \\
\text { NIST, \& }\end{array}$} \\
\cline { 2 - 3 } NIST & Ball 1 & Ball 2 \\
NPL & -0.3 & - \\
PTB & +1.6 & +2 \\
NIST & -0.2 & +4 \\
NIST (17 months later) & & +1 \\
\hline
\end{tabular}

A second intercomparison was undertaken when PTB sent four balls as part of an international round robin under the auspices of the International Bureau of Weights and Measures (BIPM) [12]. The effective accommodation coefficients of the balls were measured according to the circulated protocol at pressures be.tween $10^{-4}$ and $10^{-2} \mathrm{~Pa}$ in nitrogen, argon, and hydrogen. Several NIST and customer balls were calibrated at the same time. Unfortunately, the four balls were damaged in transit and the shifts between calibrations performed at PTB before and after the measurements at NIST were as large as 88 in hydrogen. 
A second set of four balls was, sent to NIST in 1986 in a continuation of the round robin. Preliminary results indicate that the mean of the four NIST values for argon was within $0.5 \%$ of the pilot laboratory's value. The results for nine laboratories (representing five different types of primary standard) were within \pm 28 of the pilot laboratory at argon pressures between $10^{-3}$ and $10^{-1} \mathrm{~Pa}$ with the exception of two laboratories whose values were within \pm 3 \% [13].

Several additional informal intercomparisons are underway at standards labortories. Rotors calibrated at NIST are now in use at Istituto di Metrologia "G. Colonnetti", Turin, Italy and Korea Standards Research Institute, Seoul, Korea and two calibrated MDG rotors have been sent to the National Physics Laboratory, New Dehli, India.

Intercomparisons have been carried out with other primary standards laboratories at very low flow rates using calibrated leaks as transfer artifacts [14]. Early results showed differences increasing to 108 at flow rates of $10^{-12} \mathrm{~mol} \mathrm{~s} \mathrm{~s}^{-1}$ which correspond to a nitrogen pressure of about $10^{-9}$ $\mathrm{Pa}$ in the upper chamber. It is expected that improvements since these data were taken should decrease the differences.

\section{CONTINUOUS, REPEATED CALIBRATIONS OF VACUUM GAGES}

\section{Repeat MDG Calibrations}

Many NIST-owned MDG balls have had multiple calibrations. Systematic calibrations were begun in 1983 using the gas burst method and continued with the orifice-flow standard. One rotor in particular has been calibrated repeatedly between February, 1983 and April, 1987. A total of 106 calibrations in nitrogen have been performed. The range in the effective accommodation coefficient is from 0.99 to 1.02 . These results are indicated by the dashed line in figure 5. Results of repeated calibrations for four additional balls are also shown in figure 5 . The data shown have been clarified by plotting deviations from the initial calibration expressed as a percent of that initial value and by averaging points taken within a few days of each other. There is some evidence of an increase in the effective accommodation coefficient which is expected. Large abrupt changes in the calibrations of any of the rotors have always been traced to problems with the primary high vacuum standard (such as the presence of foreign gases in the chamber, the use of unbaked rotors or failure of the turbomolecular pump) and not with the rotor surface. 
Ion gages are not as stable as MDGs and we do not expect to gain as much information about system performance from our ion gage data. However, because of the broad pressure range covered by these gages, we can use them to look for systematic errors in the high vacuum standard performance depending on whether the flow is directed into the upper or lower chamber and depending on which piston is used in measuring the flow. To date, we have not seen any systematic differences at the 28 level.

Figure 6 shows data for two ion gages. Two extensive sets of calibrations were performed on each gage between $10^{-7}$ and $10^{-1} \mathrm{~Pa}$. The two sets were performed 3 months apart. The gage in figure 6a) is designed for use between $10^{-10}$ and $10^{-2} \mathrm{~Pa}$ and showed no shift in sensitivity as a function of calibration method. Four different configurations of the flowmeter were used as well as a bank of calibrated MDGs. The gage in figure 6b) is designed for use between $10^{-8}$ and $10^{-1} \mathrm{~Pa}$ and showed a definite shift in sensitivity between the two sets of calibrations but exhibited excellent short-term stability. Again, we see no systematic differences between results using the various calibration methods. Table VI gives means and standard deviations for these two gages at $10^{-4} \mathrm{~Pa}$ for two frequently used calibration methods. It should be noted that each method of determining the pressure has a range of pressures over which it functions best. For example, we would expect more scatter in data taken at or below $10^{-4} \mathrm{~Pa}$ with an MDG than at higher pressures.

TABLE VI. Ion Gage Sensitivities, Nitrogen Gas $10^{-2} \mathrm{~Pa}^{-1}$

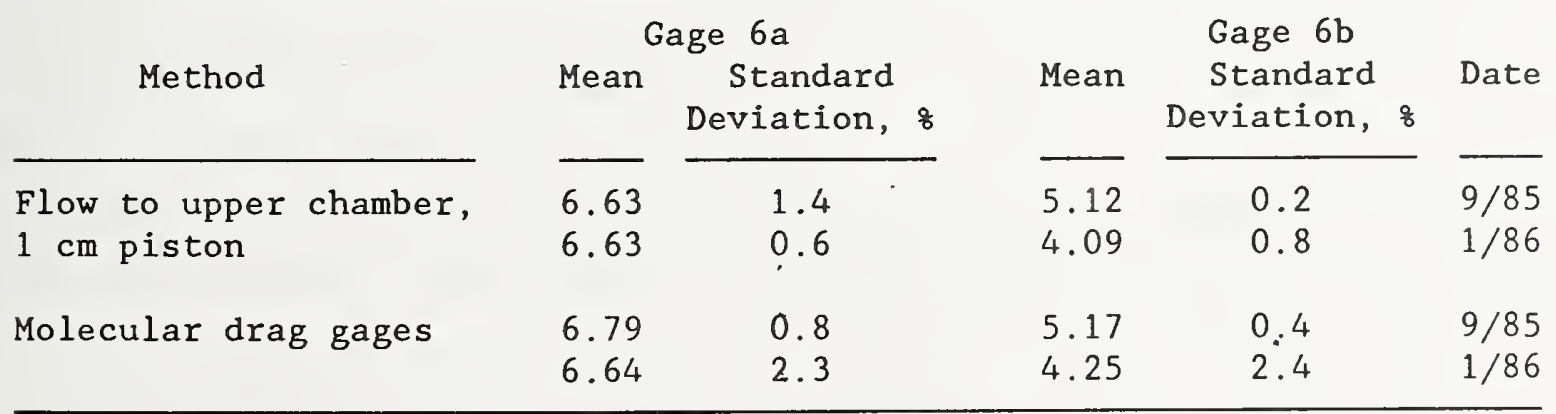

\section{ADDITIONAL CHECKS}

Eight MDGs have been returned by customers for recalibration at this time. The changes in the calibration factors varied from -2.38 in 2 year's time to +2.78 in 1.7 year's time. All of these are within our expected change 
of $1-28$ in 2 year's time. These particular customers are knowledgeable users of the gage and we expect that the rotors have been treated carefully between calibrations.

\section{NEEDS AND PLANS}

The major limitations of this system are 1) the presence of elastomer seals in the gas piston flowmeter, 2) the accuracy with which the pressure in the reference reservoir can be measured when a low fill pressure is used, and 3) the limitation of an achievable base vacuum to $10^{-8} \mathrm{~Pa}$.

In an effort to address the first limitation, we have constructed the second flowmeter which is used primarily in the primary leak standard. The differences between the two are discussed above. Future flowmeters will undoubtedly be based on the hydraulically-coupled flowmeter design in order to eliminate outgassing from the elastomer seals and to permit baking the flowmeter.

The second limitation is a major source of certainty in the flow rate measurements. We have implemented a system to permit in situ calibrations of the flowmeter CDGs with the ultrasonic interferometer manometer [15,16].

A new program is underway to develop an ultra-high vacuum standard which will help us overcome the third limitation. A major part of the work is directed toward lowering the achievable base vacuum. This has involved high temperature baking over extended periods (e.g., $500{ }^{\circ} \mathrm{C}$ for 200 hours) to reduce the room temperature hydrogen outgassing rate from the stainless steel walls of the vacuum chamber. In addition, experimentation with various types of ultra-high vacuum pumps (e.g., turbomolecular, titanium sublimation, ion, and cryogenic pumps) is in progress.

The increasing availability of ion gages designed for use under ultrahigh vacuum conditions suggests that the performance of the standard at pressures below $1 \times 10^{-6} \mathrm{~Pa}$ could be investigated using these gages as transfer standards. Expected limitations in this pressure region include the stability of the base vacuum and the linearity of the gage sensitivities and the gage residual currents.

The primary high vacuum standard is used for both experiments and calibrations, and the increasing number of calibrations means that it is becoming increasingly difficult to perform necessary experiments. One means of increasing the productivity of the system is to automate as many of the operations as possible. Certain operations lend themselves very readily to 
automation, among those being the recording of the piston drive information, the recording of $\mathrm{CDG}$ and temperature information, and the recording of MDG transfer standard readings. Those IGs which are tested on NIST-designed controllers may also be read automatically. However, we do not foresee at this time the automatic reading of customer gages owing to the large variety of instruments that are submitted for calibration.

It is hoped that automatic data acquisition will not only lead to increased productivity but will allow us to more easily document system behavior as data are collected. Both the orifice-flow standard and MDGs are relatively new and our understanding of their operation and capabilities will be expanding as new results are available. Having those results in a form amenable to ready analysis will promote optimum performance.

A second means of improving productivity is to install a larger chamber which would allow the calibration and testing of more gages at one time.

There are fundamental limitations to this system which are not amenable to treatment with equipment or technique. At the highest pressures, we have overcome the inherent limitations of the orifice by using MDGs as transfer standards. However, they become increasingly nonlinear and we have no way of calibrating them because NIST currently has no vacuum standard to cover the pressure range $10^{-2}$ to $0.5 \mathrm{~Pa}$. The orifice-flow standard and ultrasonic interferometer manometer cover the low and high pressure ends of this range but there is no provision for direct comparison. This is in part because of the mercury vapor in the manometer. One appropriate step would be to put several calibrated MDG balls on the manometer with some protection against direct mercury exposure. However, the problem of sensitivity to the molecular weight of the test gas remains for the MDGs.

We anticipate that the working range of the NIST primary high vacuum standard will remain $10^{-6}$ to $10^{-2} \mathrm{~Pa}$ for the foreseeable future. Our task at this time is to improve performance within this range with technique and equipment until our ultra-high vacuum program is well established and until a new primary standard is designed and built which will bridge the gap between the ultrasonic interferometer manometer and the flowmeter-orifice standard.

\section{ACKNOWLEDGMENTS}

We gratefully acknowledge the major contributions of Drs. K.E. McCulloh and C.R. Tilford in the conception and design of this standard and their work in the early phases of characterizing the standard. We also thank Mr. D.F. 
Martin for his efforts in the manufacture and assembly of the many components involved.

\section{REFERENCES}

[1] K. E. McCulloh, C. R. Tilford, C. D. Ehrlich, and F. G. Long, "Low-Range Flowmeters for Use with Vacuum and Leak Standards," J. Vac. Sci. Technol. A $\underline{5}, 376$ (1987).

[2] P. Clausing, Ann. Physik 12, 961 (1932); English translation appears in "The Flow of Highly Rarefied Gases through Tubes of Arbitrary Length," J. Vac. Sci. Technol. $\underline{8}, 636$ (1971).

[3] J. K. Fremerey, "The Spinning Rotor Gauge," J. Vac. Sci. Technol. A $\underline{3}$, 1715 (1985).

[4] J. K. Fremerey, "Spinning Rotor Vacuum Gauges," Vacuum 32, 685 (1982).

[5] M. Hirata, H. Isogai, M. Ono, "Effect of Measuring Conditions on the Accuracy of a Spinning Rotor Gauge," J. Vac. Sci. Technol. A 4, 1724 (1986).

[6] S. D. Wood and C. R. Tilford, "Vacuum Calibrations Using the Molecular Drag Gage," material accompanying a course given at the National Institute of Standards and Technology, Gaithersburg, Maryland.

[7] G. Comsa, J. K. Fremerey, B. Lindenau, G. Messer, and P. J. Rohl, "Calibration of a Spinning Rotor Gas Friction Gauge against a Fundamental Vacuum Pressure Standard," J. Vac. Sci. Technol. 17, 642 (1980).

[8] K. E. McCulloh, S. D. Wood, and C. R. Tilford, "Zero Stability of Spinning Rotor Vacuum Gages," J. Vac. Sci. Technol. A $\underline{3}, 1738$ (1985).

[9] R. W. Hyland, C. R. Tilford, "Zero Stability and Calibration Results for a Group of Capacitance Diaphragm Gages," J. Vac. Sci. Technol. A 3 , 1731 (1985).

[10] C. R. Tilford, S. Dittmann, K. E. McCulloh, "The NIST Primary High Vacuum Standard," J. Vac. Sci. Technol. A $\underline{6}, 2853$ (1988).

[11] K. E. McCulloh, "Calibration of Molecular Drag Vacuum Gages," J. Vac. Sci. Technol. A 1,168 (1983).

[12] G. Messer, P. Rohl, G. Grosse, W. Jitschin, "High Vacuum Measured by the - Spinning Rotor Gauge: Status Report of the Bureau International des Poids et Measures Intercomparison," J. Vac. Sci. Technol. A 5 , 2440 (1987).

[13] W. Jitschin, PTB, Private communication.

[14] C. D. Ehrlich, NIST, Private communication. 
[15] P. L. M. Heydemann, C. R. Tilford, and R. W. Hyland, "Ultrasonic Manometers for Low and Medium Vacua under Development at the National Bureau of Standards," J. Vac. Sci. and Technol. 14, 597 (1977).

[16] R. W. Hyland, "NIST Measurement Services: Calibration at the National Institute of Standards and Technology over the Low Vacuum Range from 1 to 1.5 $\times 10^{5}$ Pascal," to be published as NIST Special Publication SP 250-35.

[17] K. F. Poulter, "The Calibration of Vacuum Gauges," J. Phys. E 10, 112 (1977).

[18] R. P. Iczkowski, J. L. Margrave, and S. M. Robinson, "Effusion of Gases through Conical Orifices," J. Phys. Chem. 67, 229 (1963).

[19] D. R. Willis, "Mass Flow through a Circular Orifice and a Two-Dimensional Slit at High Knudsen Numbers," J. Fluid Mech. 21, 21 (1965).

\section{BIBLIOGRAPHY}

In addition to the references cited above, the interested reader may wish to consult the following.

\section{Intercomparisons:}

"Intercomparisons of Vacuum Standards of Countries within the European Community in the Range $8 \times 10^{-5}$ to $8 \times 10^{-2} \mathrm{~Pa}, " \mathrm{~K}$. F. Poulter, A.

Calcatelli, P. S. Choumoff, B. Iapteff, G. Messer, G. Grosse, J. Vac.

Sci. Technol. 17, 679 (1980).

"Intercomparison of the National Low Pressure Standards in the LNE and PTB," G. Messer and L. Rubet, Proceedings of the Eighth International Vacuum Congress, Cannes, France, 1980 J. P. Langeron and L. Maurice Eds., V. II, 259 (1980).

\section{Standards:}

"The Measurement of Gas Throughput in Range $10^{-4}$ to $10^{-10} \mathrm{~Pa} \mathrm{~m} \mathrm{~s}^{-1}$," G. N. Peggs, Vacuum 26, 321 (1976).

"Summary Abstract: Long-Term Stability of Low-Pressure, Standards in the German Calibration Service Deutscher Kalibrierdienst," G. Grosse and G. Messer, J. Vac. Sci. Technol. A $\underline{5}, 2463$ (1987). 
Vacuum Gage Calibration:

"Calibration of Spinning Rotor Gas Friction Gauge Against a Fundamental Vacuum Pressure Standard," G. Comsa, J. K. Fremerey, and B. Lindenau (KFA) and G. Messer and P. Rohl (PTB), J. Vac. Sci. Technol. 17, 642 (1980). "The Calibration of Vacuum Gauges," $\dot{w}$. Steckelmacher, Vacuum 37, 651 (1987).

\section{Vacuum Gages:}

"Molecular Drag on Freely Rotating Balls and Vanes," G. Comsa, J. K. Fremerey and B. E. Lindenau, Proceedings of the Eighth International Vacuum Congress, Cannes, France, 1980 J. P. Langeron and L. Maurice eds, V. II, 218 (1980).

"Long Term Stability of Various Reference Gauges over a Three Years Period," G. Messer, Proceedings of the Eighth International Vacuum Congress, Cannes, France, 1980 J. P. Langeron and L. Maurice eds, V. II, 191 (1980).

"Long Term Behaviour of Ionization Gauges," K. F. Poulter and C. M. Sutton, Vacuum 31,147 (1981).

"Spinning Rotor Vacuum Gauges," J. K. Fremerey, Vacuum 32, 685 (1982).

"Reliability of High Vacuum Measurements," C. R. Tilford, J. Vac. Sci.

Technol. A 1 , 152 (1983).

"Long-term Stability of Two Types of Hot Cathode Ionization Gauges," S. D.

Wood and C. R. Tilford, J. Vac. Sci. Technol. A $\underline{3}, 542$ (1985).

"Sensitivity of Hot Cathode Ionization Gages," C. R. Tilford, J. Vac. Sci.

Technol. A $\underline{3}, 546$ (1985).

"An Electrostatically-Suspended Spinning-Rotor Vacuum Gauge: A Feasibility

Study," J. D. Nuttall and D. C. Witt, Vacuum $\underline{37}, 347$ (1987).

"Total Pressure Gauges," R. K. Fitch, Vacuum 37, 637 (1987).

"The Use of Hot Filament Ionization Gauges," P. Nash, Vacuum 37, 643 (1987). 


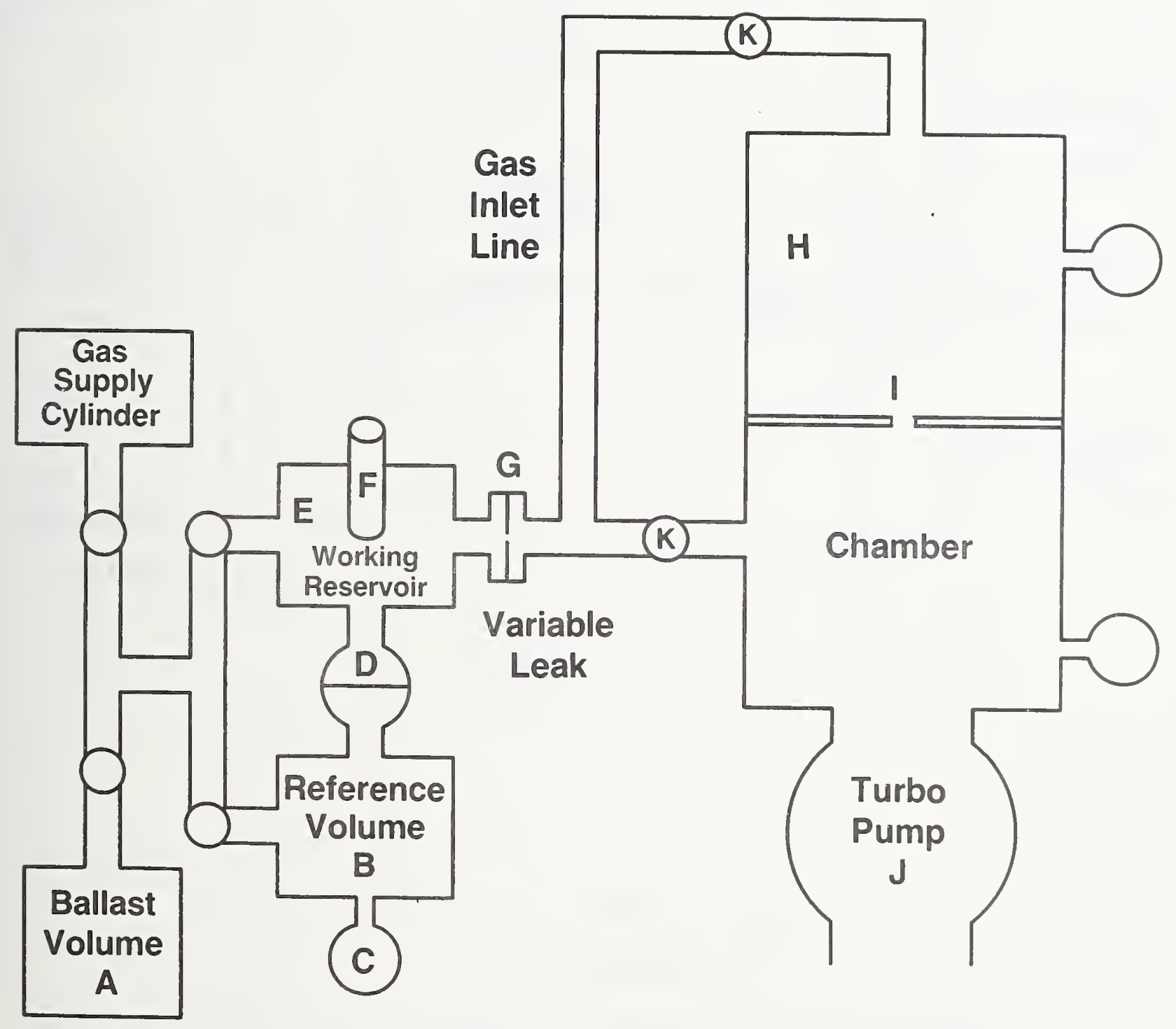

Figure 1. Schematic of the Primary High Vacuum Standard Including the Chamber, the Flowmeter and the Orifice. Letters Indicate Components which are Discussed in the Text. 


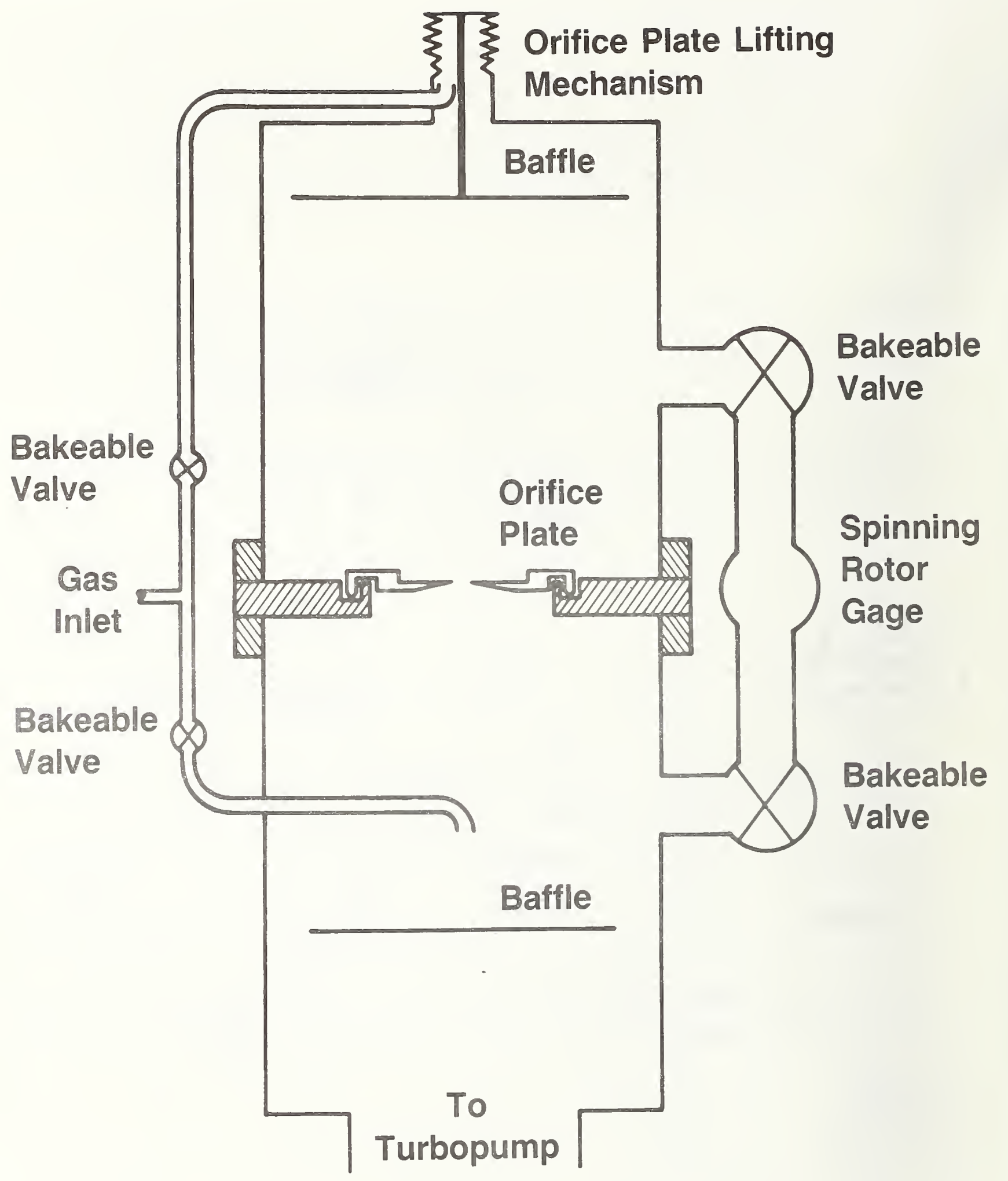

Figure 2. Schematic of the Vacuum Chamber Showing the Lifting Mechanism and Sealing Method of the Orifice Plate. Also Shown is the Arrangement of Valves and Gages Permitting the Measurement of the Upper to Lower Chamber Pressure and Flow Ratios. 


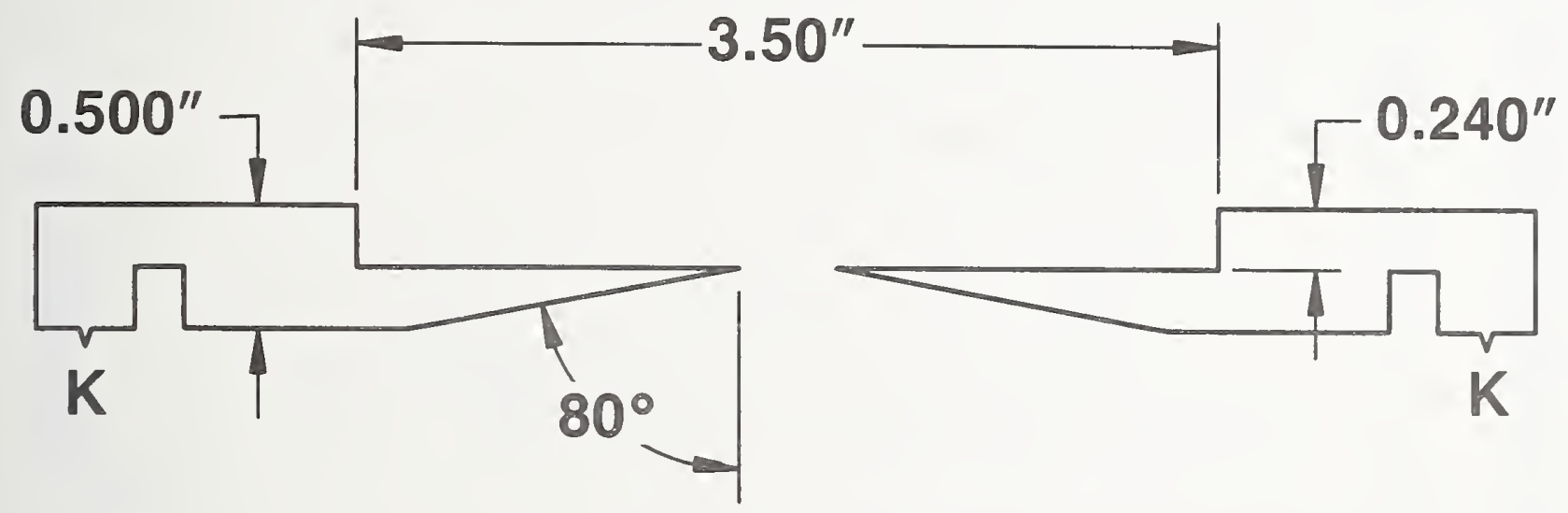

Figure 3. Axial Section of the Orifice Plate, with Dimensions in Inches. Details of the Central Duct are Shown in figure 7. This Plate can be Raised to Provide a Large Conductance Between the Upper and Lower Chambers of the Dynamic Expander During Evacuation. For Generating Calculable Pressures by Flow Through the Orifice, the Knife Edge $\mathrm{K}$ is Lowered into a Groove Gilled with Gallium to Provide a Gas-tight Seal. 


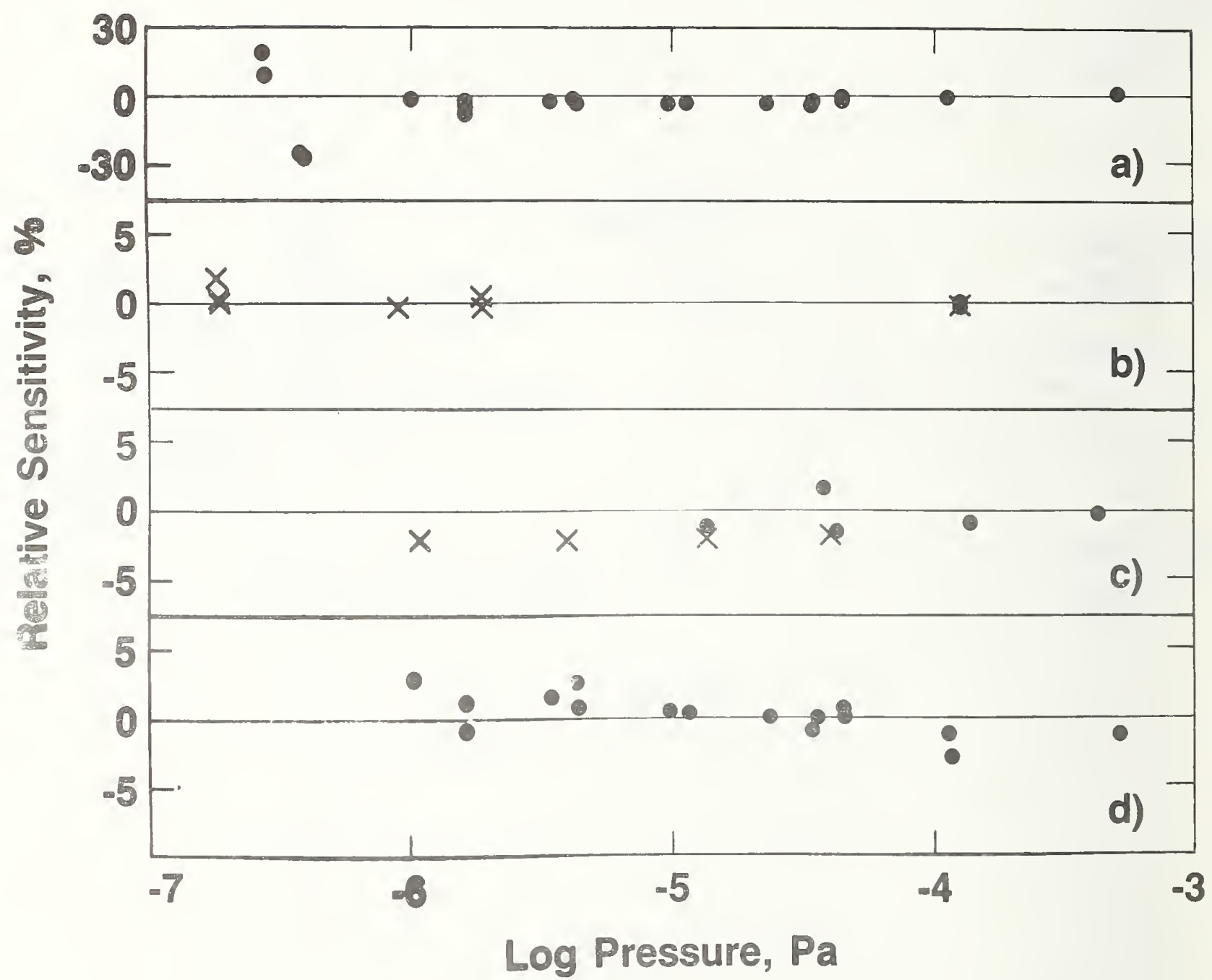

Flgure 4. Representative Measured Low-Pressure Nitrogen Sensitivities for Different Ion Gages. Sensitivities for Each Gage are Relative to its Value at $10^{-4} \mathrm{~Pa}$. The $t^{\prime} s$ Indicate Flow into the lower Chamber, the O's are into the Upper Chamber. The Data in a) are for a Nude Gage with an Electrode Structure Commonly Found in Tubulated BA Gages. The \pm 20 - $30 \%$ Variation at the Lowest Pressure is Typical of Results for Other Gages Calibrated at the Same Time. 


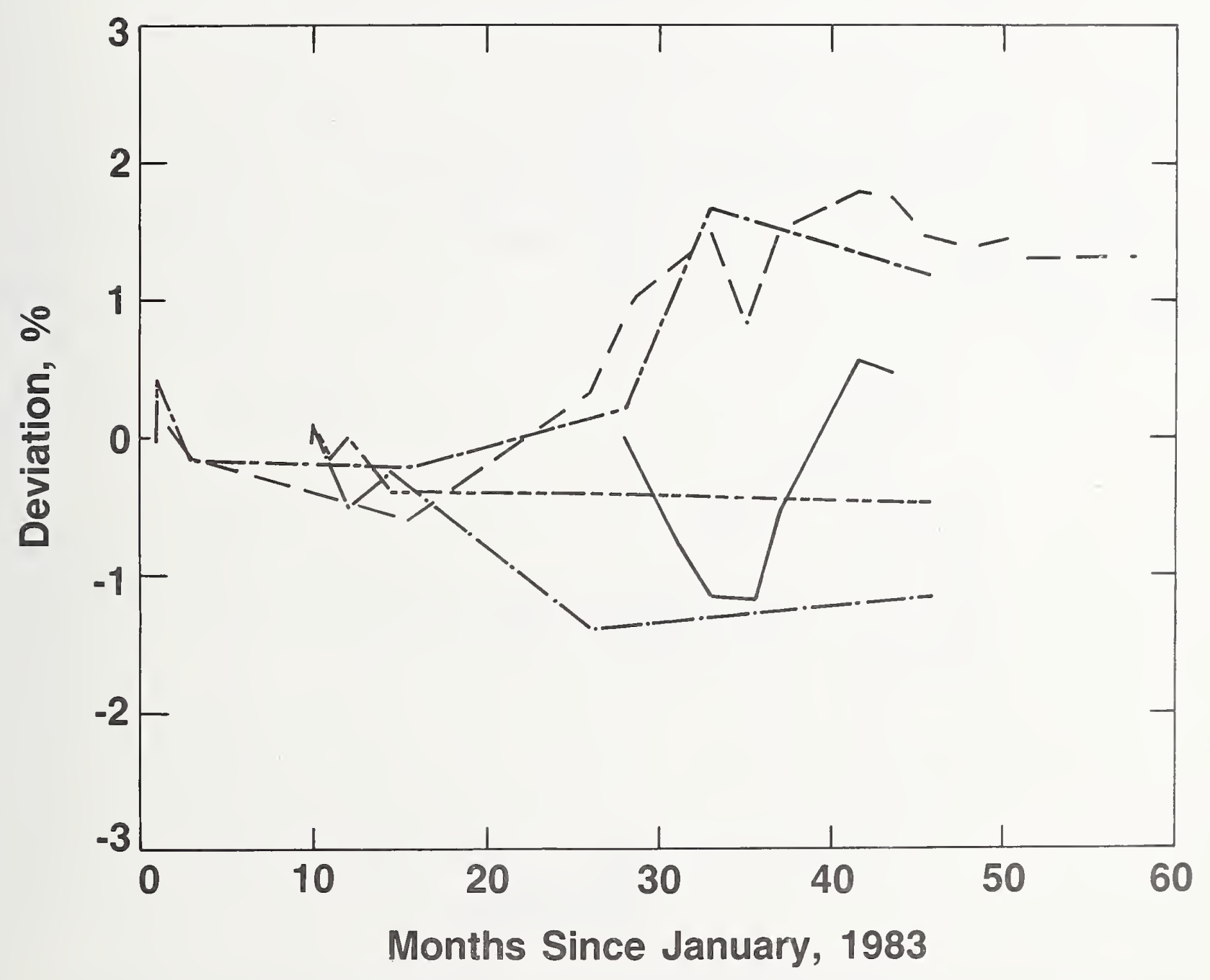

Figure 5. Deviations from the Initial Value of the Effective Accommodation Coefficient of Five Molecular Drag Gage Rotors as Determined by Calibrations Against the NIST Primary High Vacuum Standard. All Data were Taken Using Nitrogen Gas. Values have been Smoothed for Clarity by Averaging Points Taken within a Few Days of Each other. 

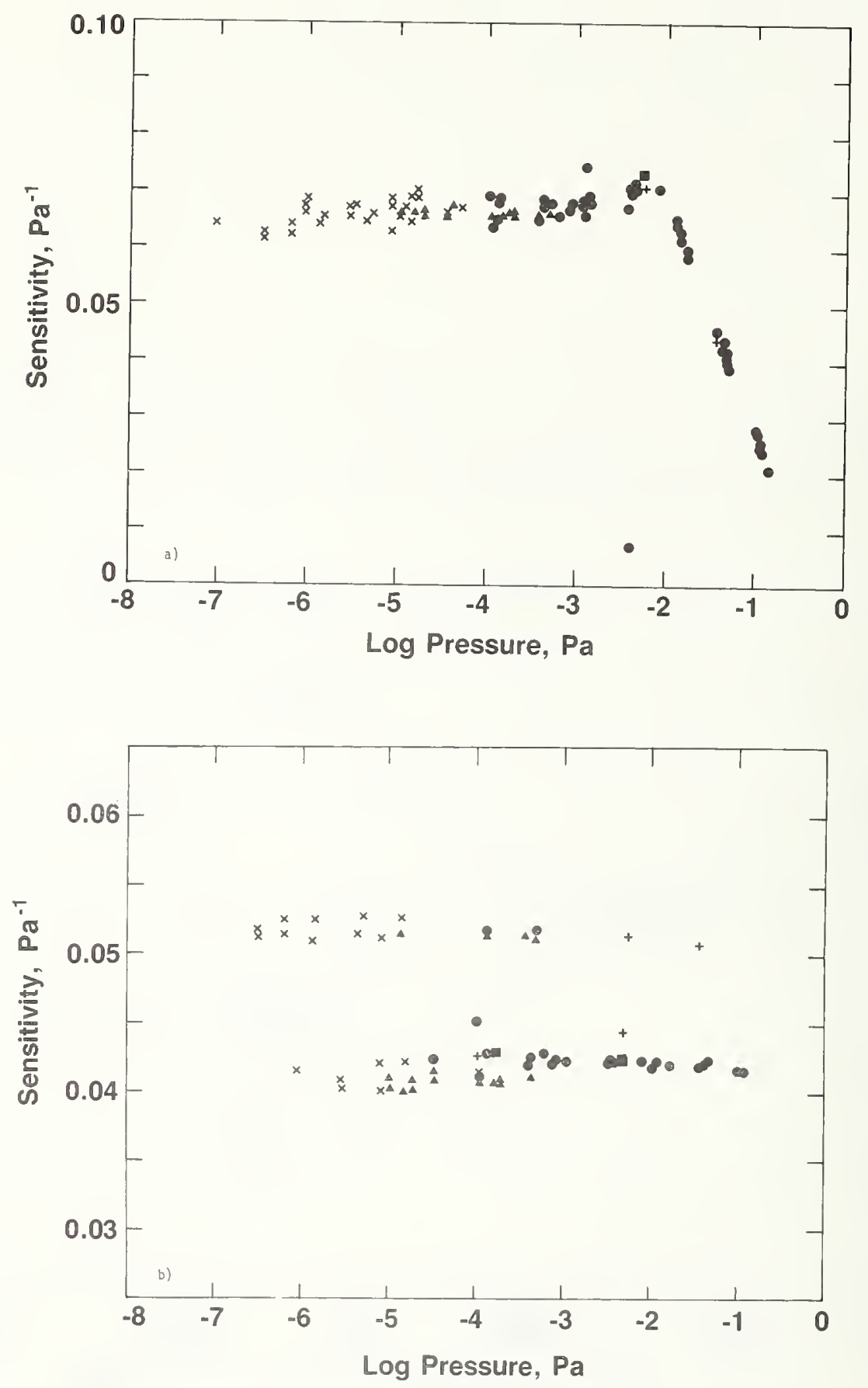

Figure 6. a) and b) Ion Gage Sensitivity in Nitrogen for Two Different Ultra High Vacuum Ionization Gages"as Determined by Calibrations Against the NIST Primary High Vacuum Standard and Against Calibrated Molecular Drag Gages. $\Delta$ - F'low into Upper Chamber, 1-cm Piston; + - Upper Chamber, 1-in Piston; X - Lower Chamber, 1-cm Piston; - Lower chamber, 1-in Piston; - Molecular Drag Gages. Gage 6a is Designed for Use Between $10^{-10}$ and $10^{-2} \mathrm{~Pa}$ and Gage $6 \mathrm{~b}$ is Designed for Use Between $10^{-8}$ and $10^{-1} \mathrm{~Pa}$. 


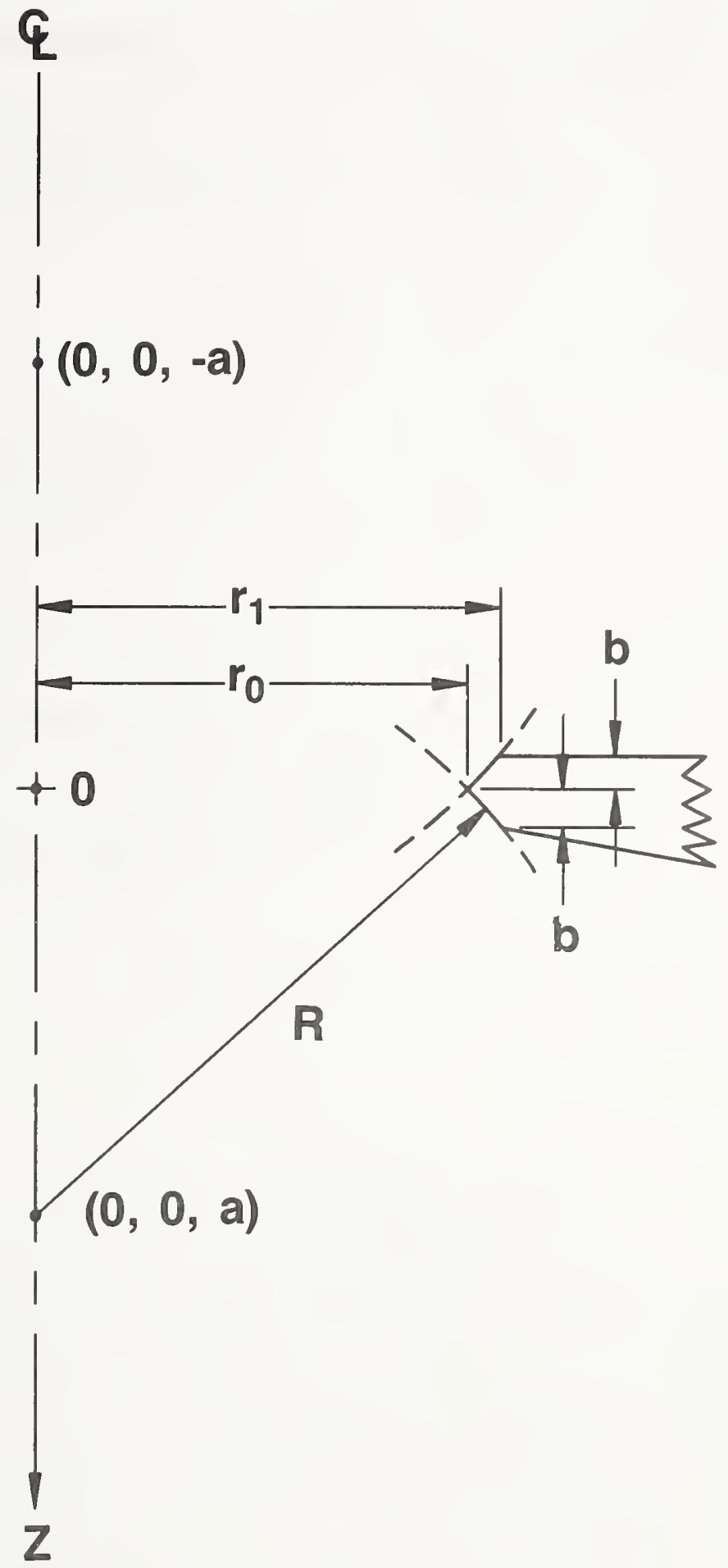

Figure 7. Detail of the Central Duct Through the Orifice Plate. The Surfaces Marked A and B are Spherical Segments Lapped to Radius of Curvature $R$, and Their Centers of Curvature are Marked with Coordinates $(0,0,-a)$ and $(0,0, a)$, Respectively. Throat and Entrance Apertures have Radii $r_{0}$ and $r_{1}$, Respectively. Planes of the Throat, Entrance Aperture, and Exit Aperture are $z=0, z=-b$, and $z=b$. Approximate Dimensions in Inches are $R=0.312, r_{0}=0.221, r_{1}=0.235, a=0.221$, and $b=0.015$. The Direction of Gas Flow is Downward. 



\title{
XI. APPENDICES
}

\section{APPENDIX A}

SAMPLE REPORT OF CALIBRATION FOR IONIZATION GAGE

Ion Gage Tube and Controller

Submitted by

CUSTOMER NAME

CITY, STATE ZIP

\author{
TPD Calibration Number: HV XX \\ NIST Identification of Gage: XXX \\ Supplier of Gage: SUPPLIER \\ Gage Model: AB123 \\ Manufacturer of Controller: MANUFACTURER \\ Controller Model: 123 \\ Controller Serial Number: 456 \\ Gas: Nitrogen
}

Date received: MONTH DAY, YEAR

Test completed: MONTH DAY, YEAR

\section{$\underline{\text { Procedures }}$}

This calibration is for a thoria-coated filament ion gage and the associated controller. The gage was calibrated with the electrode axis vertical and the collector pin up. The ambient temperature was $24{ }^{\circ} \mathrm{C}$ with free but not forced air circulation about the gage tube.

The calibration data presented in this report were obtained with the controller and gage tube operated as a unit. Operating with an emission current of $5.4 \mathrm{~mA}$ as determined by the controller, the dc filament bias was $30.9 \mathrm{~V}$ and the grid bias was $132.3 \mathrm{~V}$.

The calibration was performed on a turbomolecular-pumped, all metal chamber designed to minimize pressure gradients and maintain gas purity. The generated pressures, which are pressure increases above base vacuum, were measured with the primary vaccum standard from $10^{-6}$ to $10^{-4} \mathrm{~Pa}\left(10^{-8}\right.$ to $10^{-6}$ Torr) and with calibrated molecular drag gages from $10^{-4}$ to $10^{-1} \mathrm{~Pa}\left(10^{-6}\right.$ to $10^{-3}$ Torr). Estimated uncertainties in the generated pressures using the NIST primary vacuum standard were 18 above $1 \times 10^{-5} \mathrm{~Pa}$ increasing to \pm 58 at $1 \times 10^{-6}$ 
Pa. Using calibrated molecular drag gages, the estimated uncertainty in the generated pressure between $10^{-4}$ and $10^{-1} \mathrm{~Pa}$ is $1.68 \pm 2 \times 10^{-6} \mathrm{~Pa}$.

The gage tube was mounted on the calibration chamber and evacuated and baked overnight at $250^{\circ} \mathrm{C}$. It was degassed by being operated during the bakeout.

\section{Results}

The tube designated XXX was calibrated with the controller designated in this report from MONTH DAY to DAY, YEAR. The tube was operated with a measured emission current of $5.4 \mathrm{~mA}$ as established by the controller. All gage readings were obtained from the front panel display. The data presented below were obtained after overnight pumpdown to pressures below $5 \times 10^{-8} \mathrm{~Pa}$. The generated pressures are pressure increases above base vacuum and within each day were generated starting with the lowest and proceeding sequentially to the highest each day. The corrected controller readings were obtained by subtracting the controller reading at base conditions just prior to a calibration series from all subsequent readings. The controller readings at base conditions are due to the system base pressure and the gage residual currents. The calibration factor is the ratio of the generated pressure in Torr to the corrected controller reading.

Generated $\mathrm{N}_{2}$ Pressure

Rascal

Torr

(1 Torr=133.32 $\mathrm{Pa}$ )

\section{Controller Reading} Torr
$1.2 \times 10^{-8}$
$5.2 \times 10^{-8}$
$2.0 \times 10^{-7}$
$5.8 \times 10^{-7}$
$1.8 \times 10^{-6}$
$5.3 \times 10^{-6}$
$5.3 \times 10^{-6}$
$5.7 \times 10^{-6}$
$1.7 \times 10^{-5}$
1. $8 \times 10^{-5}$
$5.9 \times 10^{-5}$
$7.5 \times 10^{-5}$
$1.7 \times 10^{-4}$
$6.6 \times 10^{-4}$
$10.0 \times 10^{-4}$

Corrected Reading, Torr

$\begin{array}{ll}0.8 \times 10^{-8} & 0.56 \\ 1.4 \times 10^{-8} & 0.54 \\ 2.0 \times 10^{-7} & 0.54 \\ 5.8 \times 10^{-7} & 0.56 \\ 1.8 \times 10^{-6} & 0.56 \\ 5.3 \times 10^{-6} & 0.54 \\ 5.3 \times 10^{-6} & 0.54 \\ 5.7 \times 10^{-6} & 0.54 \\ 1.7 \times 10^{-5} & 0.56 \\ 1.8 \times 10^{-5} & 0.56 \\ 5.9 \times 10^{-5} & 0.53 \\ 7.5 \times 10^{-5} & 0.53 \\ 1.7 \times 10^{-4} & 0.54 \\ 6.6 \times 10^{-4} & 0.46 \\ 10.0 \times 10^{-4} & 0.48\end{array}$

0.56

0.54

0.56

0.54

.54

0.56

0.53

.53

0.46

$10.0 \times 10^{-4}$

0.48
Calibration

Factor

$4.79 \times 10^{-4}$ 
The operating parameters of the electrometer were independently checked and are noted below. for your information. The controller required approximately 24 hours after being turned on to reach a stable indication.

\begin{tabular}{cc}
$\begin{array}{c}\text { Current at Collector } \\
\text { Input Amps }\end{array}$ & $\begin{array}{c}\text { Indicated Pressure, } \\
\text { Torr, } \mathrm{N}_{2}\end{array}$ \\
\cline { 3 - 3 } $8.337 \times 10^{-10}$ & $1.0 \times 10^{-8}$ \\
$2.634 \times 10^{-9}$ & $10.0 \times 10^{-8}$ \\
$2.601 \times 10^{-9}$ & $1.0 \times 10^{-7}$ \\
$2.074 \times 10^{-8}$ & $10.0 \times 10^{-7}$ \\
$2.074 \times 10^{-8}$ & $1.0 \times 10^{-6}$ \\
$2.043 \times 10^{-7}$ & $10.0 \times 10^{-6}$ \\
$2.043 \times 10^{-7}$ & $1.0 \times 10^{-5}$ \\
$2.216 \times 10^{-6}$ & $10.0 \times 10^{-5}$ \\
$2.216 \times 10^{-6}$ & $1.0 \times 10^{-4}$ \\
$3.916 \times 10^{-5}$ & $10.0 \times 10^{-4}$
\end{tabular}

Changing emission current or bias voltages can cause changes in the gage tube sensitivity and therefore the calibration factor.

In order to obtain optimum stability from this tube, we recommend that it not be operated with significant pressures of air or oxygen, that long periods of outgassing be avoided, that after outgassing it be allowed to equilibrate for eight or more hours, and that after exposure to atmospheric air or operation with other gases it be baked out at a high temperature or wrapped in fiberglass insulation and operated for 8 hours or more in a high vacuum. An overnight equilibration period should be allowed after bakeout. Operation with $10^{-2} \mathrm{~Pa} \mathrm{~N} \mathrm{~N}_{2}$ for 1 or 2 hours followed by baking may help to stabilize subsequent $\mathrm{N}_{2}$ readings. When a sequence of pressures is to measured, the gage will perform most reliably when an increasing sequence is used. Preferably, the gage should be stabilized by operation for several hours at a pressure at least a factor of 10 below the lowest pressure to be measured. 



\section{APPENDIX B}

SAMPLE REPORT OF CALIBRATION FOR MOLECULAR DRAG GAGE

Spinning Rotor Vacuum Gage

Submitted by

CUSTOMER NAME

CITY, STATE ZIP

TPD Reference Number: HV X

NIST Identification of Flange: 654321

Manufacturer's Identification of Flange: 123456

Manufacturer: MANUFACTURER

Model Number: $A B C X Y Z$

Serial Number of Controller: 123456

Serial Number of Suspension Head: 12345

Diameter of Ball: $4.5 \mathrm{~mm}$

Gas: Nitrogen

Previous test record: HV XX

Date Received: MONTH DAY, YEAR

Test Completed: MONTH DAY, YEAR

\section{Procedure}

This unit was tested on an all-metal vacuum chamber designed to maintain a low residual gas background and minimize pressure gradients. The chamber was pumped with a turbomolecular pump to a base pressure of about $10^{-8} \mathrm{~Pa}$. After being mounted on the chamber, the thimble and ball were baked overnight in argon at $250{ }^{\circ} \mathrm{C}$ at a pressure of $10^{-4} \mathrm{~Pa}$ and then cooled slowly. After the thimble had cooled, the suspension head was installed and the ball was spun up.

During the calibration, known pressures of about $5 \times 10^{-3} \mathrm{~Pa}$ were generated in the chamber. Prior to the calibration, the residual drag of the ball was measured at a base pressure of about $10^{-8} \mathrm{~Pa}$ and was subtracted from subsequent readings. This correction must be redetermined at the time of use, as noted below.

Before calibration, the signal strength and timing uncertainty of the unit were examined. Errors of the timing circuitry were evaluated by applying a stable $200 \mathrm{uV} \mathrm{p}-\mathrm{p}, 414 \mathrm{~Hz}$ signal to the input of the electronics unit. The signal scatter (SSC) with this synthetic signal was X.Y usec. Visual inspection of the ball indicated that the surface was smooth and shiny. 
At the time of test, the pickup signal from the ball, the residual drag and the frequency dependence of the residual drag were all monitored. All of these factors may change during use and must be redetermined at the time of use. The ball was remagnetized until its signal strength exceeded $100 \mathrm{mV}$. The frequency dependence of the residual drag was checked and the residual drag was found to change from Xx10-Y $\mathrm{Pa}$ at $415 \mathrm{~Hz}$ to $\mathrm{Ax} 10^{-\mathrm{B}}$ at $405 \mathrm{~Hz}$. Corrections for frequency dependence were made in the calibration data.

\section{$\underline{\text { Results }}$}

Any number of calibrations were performed against the primary vacuum standard between MONTH DAY and MONTH DAY, YEAR. The parameters used were 28.0134 for the molecular weight of nitrogen gas, 175.7 upoise (at $298.15 \mathrm{~K}$ ) for the viscosity of nitrogen gas, $4.5 \mathrm{~mm}$ for the diameter of the ball, and $7.78 \mathrm{~g} \mathrm{~cm}^{-3}$ for the density of the ball. From these calibrations, the ball was found to have an average effective accommodation coefficient of

$$
1.00
$$

in nitrogen gas for pressures less than $10^{-1} \mathrm{~Pa}$. The residual standard deviation of the measured effective accommodation coefficients was $0 . X \%$. The estimated total uncertainty of the NIST primary standard used for this calibration is 1.5\%. Nonlinearities in the gage, not included in the above effective accommodation coefficient will increase with pressure and amount to about $0.1 \%$ at $0.05 \mathrm{~Pa}$ and $1 \%$ at about $0.5 \mathrm{~Pa}$. Corrections are made for this nonlinearity by the controller using the viscosity data entered by the user. The uncertainty in this correction had not been quantified.

Please note that the parameters for this ball and gas constitute an integral part of the calibration. For the proper use of this calibration, the operating temperature and the appropriate viscosity must be entered and the other parameters must remain unchanged.

\section{Discussion}

This ball was calibrated as part of a system consisting of the ball, the thimble, the suspension head and the controller. We expect that the effective accommodation coefficient will depend primarily on the properties of the ball and the ball's surface. However, we cannot predict the effect on the effective accommodation coefficient of changing the other components of the system. 
The effective accommodation coefficient given for the ball applies only for nitrogen.

Before the gage is used, the chamber temperature, in kelvins, must be entered from the front panel of the controller as a parameter. Temperature corrections must be made for the viscosity, and the residual drag must be determined for the temperature of use.

Care must be exercised in using a spinning rotor gage to achieve optimum performance. For use at the lowest pressure, the ball and thimble should be baked with the vacuum system. Mechanical or chemical damage to the surface of the ball should be avoided and the ball should always be stopped before it is lowered in the thimble. External magnetic fields (time dependent fields in particular) will have an unpredictable effect on the behavior of the unit. To obtain the optimum rotational timing signal, it may be necessary to periodically remagnetize the ball, particularly after it has been baked.

Since the magnitude of the residual drag can change, it must be redetermined each time the ball is suspended, and preferably before each series of low pressure measurements. The residual drag should be determined by monitoring the indicated pressure at "zero" pressure. The most accurate values will not be obtained until 5 to 7 hours after spinning up the ball from rest. This allows for dissipation of the ball's induced heat. The frequency dependence of the residual drag can change as well when the ball is resuspended, and therefore should be checked.

The error of a measurement made with this gage, assuming pure nitrogen and appropriate parameters, will include the $1.5 \%$ uncertainty of the NIST standard, random reading errors of the gage, and any shift in the effective accommodation coefficient as a function of time because of changing ball surface conditions. Random reading errors will depend on the strength of the rotational timing signal, the measurement time and local temperature and vibrational instabilities. They should be evaluated by the user by observing repeated measurements at a stable pressure. This is most easily accomplished by making repeated observations of the indicated zero or residual drag at low $\left(<10^{-6} \mathrm{~Pa}\right)$ pressure. Operating the ball in a different thimble from the one in which it was calibrated may change the calibration by up to $1 \%$. The mechanisms contributing to this change are not well understood. Experience to date indicates that if the ball is not mechanically scuffed or exposed to aggressive gases, changes in the effective accommodation coefficient should be less than 28 over 1 or 2 year's time. 

DIMENSIONS AND CONDUCTANCE OF THE ORIFICE

IN THE NIST DYNAMIC EXPANDER*

\section{Introduction}

The orifice in the NIST dynamic expansion apparatus was designed and fabricated in 1980 to satisfy three conditions:

1. Sufficient thickness to ensure dimensional stability,

2. A molecular flow conductance differing by less than 18 from that of an infinitely thin orifice having the same diameter, and

3. A geometric form to facilitate accurate calculation of this conductance by the integral equation method introduced by Clausing [2] . An orifice with a sharp circular edge in the plane of minimum cross section best satisfies these conditions. Spherical geometry was chosen for the surfaces meeting at this edge in order to facilitate the conductance calculations. In addition, these surfaces could be generated by lapping.

A generalization of Clausing's theory is required because of the departure from cylindrical geometry. Although the present formulation emphasizes probabilities for retrograde escape from the orifice duct, while Clausing's is based on forward escape probabilities, the two are equivalent. Either formulation can be derived from the other or directly from first principles.

\section{$\underline{\text { Structure and Dimensional Details }}$}

An axial section of the orifice plate as designed and fabricated of stainless steel is shown in figure 3 , and details of the central duct appear in figure 7. The two surfaces $A$ and $B$ in figure 7 are spherical segments generated by lapping to a radius of curvature $R=0.3125$ in. The diameter of the throat where these surfaces meet at a sharp edge was measured at NIST by R. Veal and $W$.

*A Technical Report submitted by The Catholic University of America to the Temperature and Pressure Division of the National Institute of Standards and Technology in Compliance with the Terms of Grant NB82NAHA3005, K E. McCulloh, Frincipal Investigator. 
Gallagher, who reported a value $2 r_{0}=0.4425$ in $\pm 0.00003 \mathrm{in}$, where $\mathrm{r}_{0}$ is the radius. Each of thẹ spherical segments terminates at an axial distance $\mathrm{b}=0.0150$ in \pm 0.0005 in from the plane of the throat. Transition to the full thickness of the orifice plate is made above by a cylindrical step 0.240 in high at a diameter of 3.50 in, and below by a truncated cone 0.230 -in high with an apex half-angle of $80^{\circ}$.

Microscopic examination gave no evidence for burrs or significant irregularities at the throat edge. The edge angle computed from the above dimensions is $90.1^{\circ}$, in close agreement with the nominal design value of $90^{\circ}$, which was chosen specifically for the purpose of minimizing burr formation.

\section{Calculation of the Molecular Flow Conductance}

Rectangular coordinate axes Oxyz are chosen with the origin in the center of the throat and the axis $\mathrm{Oz}$ in the axis of rotational symmetry. The axial coordinate $z$ increases downward, in the direction of flow. Symbols are listed in Appendix C-I. The plarie of the throat is assumed to be a plane of symmetry for the central duct. Any error from this assumption is absorbed within the error bounds assigned to dimension $b$. The cross sections in the planes $Z=-b$ and $Z=b$, where the surfaces $A$ and $B$ terminate, will be referred to as entrance and exit apertures, respectively. Centers of curvature for surfaces $A$ and $B$ are at the points $(0,0,-a)$ and $(0,0, a)$, respectively, where $a^{2}=R^{2}-r_{0}^{2}$.

Following Poulter [17], the molecular conductance L can be adequately approximated in the form

$$
\mathrm{L}=\pi \mathrm{r}_{1}{ }^{2} \mathrm{WK}_{1} \mathrm{~K}_{2} \overline{\mathrm{c}} / 4
$$

where $r_{1}$ is the entrance aperture radius. The molecular transmission probability $W$ of the central duct is to be calculated by neglecting the cylindrical step above the plane $z=-b$ and the conical transition below the plane $z=b$. This neglect requires the introduction of two correction factors: $K_{1}$ for the effect of the step and $K_{2}$ for that of the cone. The symbol $\bar{c}$ represents the mean molecular speed in a Maxwellian distribution.

No adequate basis for estimating $\mathrm{K}_{1}$ has been found in the literature. Indeed, the draft international standard ISO/DIS 3570/I for dynamic expanders requires no correction for a step having the dimensions given above. Although a complete analysis of this subject is beyond the scope of this report, simple estimates based on a generalization of Clausing's theory [2] provides the bounds 


$$
0.99995<\mathrm{K}_{1}<0.99997 .
$$

A carefully designed conical transition in place of an abrupt step would require a correction factor much closer to unity. Unfortunately, design and fabrication preceded recognition of this point.

From the computed results and uncertainty estimates published by Iczkowski et al. [18] fcr conical orifices

$$
0.9999 \leq \mathrm{K}_{2} \leq 1.0000 \text {. }
$$

On the basis of these inequalities a nominal value of 0.9999 for the product $\mathrm{K}_{1} \mathrm{~K}_{2}$ is employed in the subsequent computations.

The transmission probability $W$ remains to be calculated. It is assumed that molecules from a solid angle $2 \pi$ of a Maxwellian distribution enter the central duct through the entrance aperture and that the wall, consisting of surfaces $A$ and $B$, scatters impacting molecules according to the cosine law. Clausing's treatment of this law [2] provides a basis for calculating several probabilities required for the conductance calculation. These probabilities, which depend only upon axial coordinates because of rotational symmetry, are defined as follows:

$h(z)$ : Points of initial impact on the wall by molecules entering the duct through the entrance aperture are distributed with respect to $z$ with probability density $\mathrm{h}(\mathrm{z})$.

$g(u, z)$ : If the axial coordinate has the value $u$ at a scattering point $P$ on the wall, points of next impact $\mathrm{n}$ the wall by molecules scattered from $P$ are distributed with respect to $z$ with probability density $\mathrm{g}(\mathrm{u}, \mathrm{z})$.

$p_{0}(z)$ : Molecules scattered from the wall at $(x, y, z)$ make direct line-of-sight escape back through the entrance aperture with probability $p_{0}(z)$.

$\mathrm{p}(\mathrm{z})$ : Molecules scattered from the wall at $(\mathrm{x}, \mathrm{y}, \mathrm{z}$ ) made eventual escape (direct plus indirect) back through the entrance aperture with probability $p(z)$, which equals $p_{0}(z)$ plus the probability of escape after again striking the wall one or more times.

$w(z)$ : Molecules scattered from the wall at $(x, y$,$) make eventual forward$ escape through the exit aperture with probability $w(z)$. As the walls are assumed not to capture molecules, $p(z)+w(z)=1$.

If $W$ is the molecular transmission probability of the orifice, the complementary probability $1-W$ is given by the integral 


$$
1-W=\int_{-b}^{b} h(z) p(z) d z
$$

where $p(z)$, translating its verbal definition into mathematical form, is the solution of the inhomogeneous Fredholm integral equation of the second kind

$$
p(z)=p_{0}(z)+\int_{-b}^{b} g(z, u) p(u) d u
$$

These two equations provide the basis for the conductance calculation.

The probabilities and probability densities appearing in these equations depend only on geometric parameters, not on any particular distribution of molecular flux. Hence they must hold at equilibrium, where conditions for detailed balance lead to the reciprocal relations

$$
\pi r_{1}^{2} h(z)=2 \pi R p_{0}(z)
$$

and

$$
\mathrm{g}(\mathrm{z}, \mathrm{u})=\mathrm{g}(\mathrm{u}, \mathrm{z}) .
$$

The factor $2 \pi R$ occurs in eq (C4) and the kernel $g(z, u)$ is symmetric because the differential $2 \pi R d z$ is an element of wall area. Also, because the plane $z=0$ is a plane of symmetry for the central duct, $w(z)=p(-z)$. Since $p(z)+w(z)=1$,

$$
\mathrm{p}(\mathrm{z})+\mathrm{p}(-\mathrm{z})=1
$$

No further use of the forward escape probability $w(z)$ is required.

From eqs (C2) and (C4).

$$
r_{1}^{2}(1-W)=2 R \quad \int_{-b}^{b} p_{0}(z) p(z) d z .
$$

This form is useful because expressions for $p_{0}(z)$ can be conveniently formulated.

From Clausing's auxiliary theorems, [2]

$$
2 \mathrm{Rp}(z)=\mathrm{R}+\mathrm{a}-\mathrm{b} ; \quad-\mathrm{b}<\mathrm{z}<0,
$$

and equating two expressions for the probability that a molecule scattered from the wall will next pass through the throat,

$$
\mathrm{P}_{\mathrm{o}}(\mathrm{z})+\int_{-b}^{0} \mathrm{~g}(\mathrm{z}, \mathrm{u}) \mathrm{du}=(\mathrm{R}-\mathrm{a}) /(2 \mathrm{R}) ; \quad 0<\mathrm{z}<\mathrm{b}
$$

Further, if $\mathrm{z}$ and $\mathrm{u}$ are both positive or both negative,

$$
2 \operatorname{Rg}(z, u)=1 \text {. }
$$


Because of eq (C6) it suffices to expand the integral eq (C3) only in the range of positive $z$. After some manipulation the result becomes

$$
2 R p(z)=R-a+A-2 R \int_{0}^{b} g(-z, u) p(u) d u ; \quad 0<z<b,
$$

where

$$
A \cdot=\int_{0}^{b} p(u) d u
$$

Integrating eq (C8),

$$
(2 R-b) A=b(R-a)-B
$$

where

$$
B=2 R \int_{-b}^{0} d z \int_{0}^{b} g(z, u) p(u) d u
$$

Substituting for $p_{0}(z)$ in, eq (C7) and introducing an effective transmission probability $\mathrm{K}$ based on throat area $\pi \mathrm{r}_{0}{ }^{2}$, where

$$
\begin{gathered}
r_{0}{ }^{2} \mathrm{~K}=\mathrm{r}_{1}{ }^{2} \mathrm{~W}, \\
\mathrm{r}_{\mathrm{o}}{ }^{2}(1-\mathrm{K})=\mathrm{b}(\mathrm{R}-\mathrm{a})-(2 \mathrm{a}-?) \mathrm{A}-\mathrm{B}
\end{gathered}
$$

Eliminating the double integral B from eqs (C9) and (C11) yields the unexpectedly simple result

$$
\mathrm{K}=1-2 \mathrm{~A} /(\mathrm{R}+\mathrm{a})
$$

while eq (C1) becomes

$$
\mathrm{L}=\pi \mathrm{r}_{0}{ }^{2} \mathrm{KK}_{1} \mathrm{~K}_{2} \overline{\mathrm{c}} / 4 \text {. }
$$

Equation (C13) is preferable to eq (C1) for assigning uncertainties because the uncertainty of 0.148 in the area factor $\pi r_{0}{ }^{2}$ is dominant, while that in the factor $\mathrm{K}$ is only about 0.038 , and that in the product $\mathrm{K}_{1} \mathrm{~K}_{2}$ is estimated to be about 0.018 . The uncertainty in $\mathrm{K}$ is due almost entirely to the assigned imprecision in the dimension $b$. Hence with $K=0.99167$ from Appendix $B$ and $k_{12}=0.9999$, the final result becomes

$$
\mathrm{L}=0.9916 \cdot \pi \mathrm{ro}_{\mathrm{o}}{ }^{2} \mathrm{c} / 4 \text {, }
$$

with an uncertainty of 0.048 for the formula and an additional 0.148 when the measured value is assigned to the throat diameter.

The molecular flow conductance is proportional to the square root of the absolute temperature through the factor $\bar{c}$. Values for several gases at 298.25 $\mathrm{K}$ are tabulated below, with an estimated uncertainty of 0.188 . 


$\begin{array}{lc}\mathrm{H}_{2} & 43.52 \\ \mathrm{He} & 30.89 \\ \mathrm{~N}_{2} & 11.675 \\ \mathrm{Ar} & 9.777\end{array}$

The effect of deviations from the cosine law of scattering is beyond the scope of this report. A simple model, based on the assumption that a small fraction of molecules undergoes specular reflection, suggests that the small difference $1-\mathrm{K}$ is roughly proportional to the fraction of molecules undergoing cosine law scattering.

The correction for finite Knudsen number in the transition region near the limit of free molecular flow will require an empirical approach. The theoretical treatment by Willis applies to an ideal infinitely thin orifice with zero pressure on the downstream side [19]

\section{Conclusion}

The orifice in the NIST dynamic-expander satisfles the three conditions stated in the Introduction. The simple form of eq (C12) and the ability to impose narrow bounds on the transmission probability are consequences of the spherical geometry and the symmetxy of the central duct with respect to the place of the throat. Application of more precise dimensional metrology would decrease the uncertainty in the calculated conductance. 


\section{List of Symbols}

R: radius of curvature of surfaces $A$ and $B$ (fig. 7).

$r_{0}$ : radius of the throat.

a: distance from the center of the throat to the center of curvature of surface $A$ or surface $B . a^{2}=R^{2}-r_{0}{ }^{2}$

b: distance from the center of the entrance aperture to the center of the throat; also from the center of the throat to the center of the exit aperture.

$r_{1}$ : radius of the entrance (exit) aperture. $r_{1}{ }^{2}=R^{2}-(a-b)^{2}$

L: molecular flow conductance of the orifice.

$\bar{c}$ : mean molecular speed. $\bar{c}^{2}=8 \mathrm{kT} /(\pi \mathrm{m})$

$W, K, h(z), g(z, u), P_{0}(z), P(z), w(z)$ : probabilities defined in text. 

The Integral $A$ and the Transmission Probability $K$

The integral $A$ and the transmission probability $K$ have been narrowly bounded without solving integral eq (C8). First the integrals

$$
I(z)=2 R \int_{0}^{b} g(z, u) d u ; \quad-b<x<0
$$

and

$$
J=\int_{-b}^{0} I(z) d z
$$

were evaluated by numerical quadrature. Although a suitable analytical expression for $g(z, u)$ has not been found, arguments based on the spherical geometry and Clausing's first auxiliary theorem [2] identify the product $2 \pi R I(z)$ with a particular area on the (mathematical) sphere of which surface $A$ (fig. 7) is a segment. This is the area traversed by molecules scattered from a point $(x, y, z)$ on surface $A$ and next striking surface $B$.

The quadratures were performed in BASIC on a minicomputer by Simpson's rule. Several hours of running time on the otherwise idle computer were required. The grid was sufficiently fine to compute $I(z)$ at 101 points with an uncertainty less than $0.001 \mathrm{~b}$. The integral $\mathrm{J}$ was computed with an uncertainty less than $0.001 \mathrm{~b}^{2}$.

Absolute bounds based on generous overestimates of uncertainty yield the inequalities

$$
I_{1}=0.63 \cdot b<I(z)<0.79 \cdot b=I_{2} ; \quad-b<z<0,
$$

and

$$
\mathrm{J}_{1}=0.69 \cdot \mathrm{b}^{2}<\mathrm{J}<0.71 \cdot \mathrm{b}^{2}=\mathrm{J}_{2} \cdot
$$

Then if $p_{1}, P_{2}, A_{1}$, and $A_{2}$ are absolute bounds such that

$$
\mathrm{p}_{1}<\mathrm{p}(\mathrm{z})<\mathrm{p}_{2} ; \quad 0<\mathrm{z}<\mathrm{b},
$$

and

$$
A_{1}<A<A_{2} \text {, }
$$

one obtains from eqs (C8) and (C9) the system

$$
\begin{gathered}
2 R p_{1}=R-a+A_{1}-I_{2} p_{2}, \\
2 R p_{2}=R-a+A_{2}-I_{1} P_{1}, \\
(2 R-b) A_{1}=b(R-a)-J_{2} p_{2}, \\
(2 R-b) A_{2}=b(R-a)-J_{1} p_{1} .
\end{gathered}
$$


Assigning nominal values to the orifice dimensions and solving this system for the bounds,

$$
0.14763<\mathrm{p}(\mathrm{z})<0.14822 ; \quad 0<\mathrm{z}<\mathrm{b}
$$

and

$$
0.14792 \cdot \mathrm{b}<\mathrm{A}<0.14801 \cdot \mathrm{b} \text {. }
$$

From eq (C12) and these bounds on $A$,

$$
0.991672<\mathrm{k}<0.991677 \text {. }
$$

Hence $\mathrm{K}=0.99167$ to five decimal places, with an uncertainty of $0.03 \%$ due to dimensional imprecision.
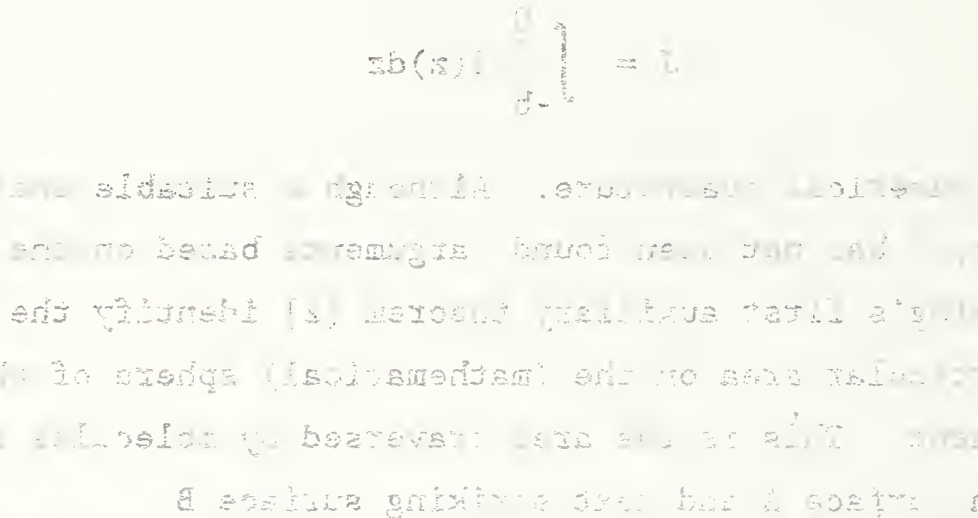
BIBLIOGRAPHIC DATA

SHEET (See instructions)

1. PUBLICATION OR
REPORT NO.
NIST/SP-250/34

2. Performing Organ. Report Nof 3. Publication Date

March 1989

4. TITLE AND SUBTITLE

NIST Measurement Services: High Vacuum Standard and Its Use

5. $\operatorname{AUTHOR}(S)$

Sharrill Dittmann

6. PERFORMING ORGANIZATION (If joint or other than NBS, see in structions)

MATIONAL INSTTUUTE OF STANDARDS AND TECHNOLOGY

(lormerty MATIONAL BUREAU OF STANDARDS)

U.S. DEPAATMENT OF COMMEACE

CATTHERSEURG, MD 20099

9. SPONSORING ORGANIZATION NAME AND COMPLETE ADDRESS (Sireet, CIIY, Stote; ZIP)

7. Contract/Grant No.

Same as Item \#6

10. SUPPLEMENTARY NOTES

Library of Congress Catalog Card Number: 88-600605

[.] Document describes a computer program; SF-185, FIPS Software Summary, is attached.

11. ABSTRACT (A 200-word or less factual summary of most significant information. If document includes a significant bibliography or literature survey. mention it here)

This document presents an in-depth discussion of the National Institute of Standards and Technology primary high vacuum standard, used between $10^{-6}$ and $10^{-2}$. $\mathrm{Pa}$. Included are discussions of the theory, design, and construction of the standard. In addition, the systematic and random errors in the standard and the methods used to check the accuracy of the standard are presented. Also included is a brief discussion of the polecular drag gage and its use as a transfer standard between $10^{-4}$ and $10^{-1} \mathrm{~Pa}$.

12. KEY WORDS (Six to twelve entries; alphabetical order: capitalize only proper names: and sedarate key words by semicolons) dynamic expander; flowmeter; high vacuum standard; ionization gage calibration; molecular drag qage; orifice conductance; orifice-flowmeter system; primary high vacuum standard; spinning rotor gage; vacuum gage calibration

13. AVAILABILITY

$\mathrm{X}$ Unlimited

For Official Distribution. Do Not Release to NTIS

$\square$ Order From Superintendent of Documents, U.S. Government Printing Office, Washington, D.C. 20402.

Order From National Technical Information Service (NTIS), Springfield, VA. $2216 I$

14. NO. OF PRINTED PAGES

68

15. Price 



SP 250-1 Spectral Radiance Callbrations

SNO03-003-02792-8 $\$ 3.50$

SP 250-2 Far Ultraviolet Detector Standards PB87227609

SP 250-3 Radometric Standards in the Vacuum Ultraviolet

PB87227625

SP 250-4 Fricke Dosimetry in High-Energy Electron Beams SN003-003-02816-9 \$2.75

SP 250-5 Alpha-Particle Calibrations SN003-003-02823-1 $\$ 2.00$

SP 250-6 Regular Spectral Transmittance PB88108550

SP 250-7 Radiance Temperature Callbrations SNO03-003-02827-4 \$2.25

SP 250-8 Spectral Reflectance PB88109905

SP 250- Calbration of Beta-Particle-Emitting Ophthalmic Applicators SNOO3-003-02817-7 \$2.00

SP 250-10 Radloactivity Callbrations wth the " $4 \pi$ " Garmma lonization Chamber and Other Radioactivity Callbration Capabilitles SN003-003-02824-0 \$2.25

SP 250-11 Dosimetry for High Dose Applications PB88201587

SP 250-12 Neutron Personnel Dosimetry SNO03-003-02811-8 $\$ 2.50$

SP 250-13 Activation Foll Irradlation with Calitornlum Flssion Sourcas SNO03-003-02866-5 $\$ 2.25$

SP 250-14 Activation Foil Irradiation by Reactor Cavity Flssion Sources SN003-003-02861-4 \$3.25

SP 250-15 Photometric Callbrations PB88153747

SP 250-16 Callbration of X-Ray and Gamma-Ray Measuring Instruments SN003-003-02862-2 \$7.00

SP 250-17 The NBS Photodetector Spectral Response Callbration Transfer Program SN003-003-02857-6 \$3.25
SP 250-18 Neutron Source Strength Calibrations SN003-003-02863-1 \$3.25

SP 250-19 Callbration of Gamma-Ray-Emittirg Brachytherapy Sources SN003-003-02923-8

SP 250-20 Spectral Irradlance Callbrations SN003-003-02829-1 \$5.50

SP 250-21 Callbration of Beta-Particle Radlation instrumentation PB88201579

SP 250-22 Platinum Reslstance Thermometer Callbrations PB88138367

SP 250-23 Luqid-In-Glass Thermometer Callbration Service SN003-003-02891-6 \$6.00

SP 250-24 Standard Cell Calbrations PB88123690

SP 250-25 Callbration Service for Inductive Voltage Dividers

SP 250-26 NBS Phase Angle Callbration Services SN003-003-02871-1 $\$ 5.00$

SP 250-27 AC-DC Difference Callbrations

SP 250-28 Solld-State DC Voltage Standard Calibrations SN003-003-02842-8 $\$ 2.00$

SP 250-29 Traceable Frequency Callbrations SN003-003-02844-4 $\cdot \$ 2.25$

SP 250-30 GOES Satellite Time Code Dissemination: Description and Operation SN003-003-02845-2 \$2.75

SP 250-31 Mass Callbrations SN003-003-02919-0

SP 250-32 A Calibration Service for $30 \mathrm{MHz}$ Attenuation and Phase Shlift SN003-003-02875-4 \$13.00

SP 250-33 A Calibration Service for Voltage Transformers and High-Voltage Capactors SN003-003-02880-1 \$1.25

SP 250-34 High Vacuum Standard and lits Use

* Those entrles contalining a stock number (003-003-- $\rightarrow$ and price can be purchased from the Superintendent of Documents, U.S. Government Printing Office, Washington, DC 20402. GPO will accept checks, money orders, VISA, and Mastercharge. For more Information, or to place an order, call (202) 783-3238. Be sure to use the stock number In all orders.

Entrles containing PB numbers can be purchased from the National Technlcal Information Service, Springfield, VA 22161. NTIS will accept American Express In addition to the payment methods Ilsted for GPO. For more information call (703) 487-4650; to place an order call (800) 336-4700. Be sure to use the PB number on all orders.

Titles without stock numbers are in preparation. 
U.S. Department of Commerce

Natlonal Institute of Standards and Technology

(formerly Natlonal Bureau of Standards)

Galthersburg, MD 20899

Officlal Business

Penalty for Private Use $\$ 300$ 